\title{
Modification of Cobalt Oxide Electrochemically Deposited on Stainless Steel Meshes with Co-Mn Thin Films Prepared by Magnetron Sputtering: Effect of Preparation Method and Application to Ethanol Oxidation
}

\author{
Květa Jirátová ${ }^{1, *}$, Roman Perekrestov ${ }^{2}$, Michaela Dvořáková ${ }^{3}$, Jana Balabánová ${ }^{1}$, Martin Koštejn ${ }^{1}$,

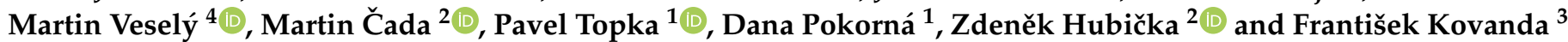 \\ check for \\ updates \\ Citation: Jirátová, K.; Perekrestov, R.; \\ Dvořáková, M.; Balabánová, J.; \\ 1 Institute of Chemical Process Fundamentals, Czech Academy of Sciences, Rozvojová 135 \\ 16502 Prague, Czech Republic; balabanova@icpf.cas.cz (J.B.); kostejn@icpf.cas.cz (M.K.); \\ topka@icpf.cas.cz (P.T.); pokorna@icpf.cas.cz (D.P.) \\ 2 Institute of Physics, Czech Academy of Sciences, 18200 Prague, Czech Republic; info@fzu.cz (R.P.); \\ cada@fzu.cz (M.Č.); hubicka@fzu.cz (Z.H.) \\ 3 Department of Solid State Chemistry, University of Chemistry and Technology, \\ 16628 Prague, Czech Republic; info@vscht.cz (M.D.); Frantisek.Kovanda@vscht.cz (F.K.) \\ 4 Department of Organic Technology, University of Chemistry and Technology, 16628 Prague, Czech Republic; \\ veselyr@vscht.cz \\ * Correspondence: jiratova@icpf.cas.cz; Tel.: +420-220-390-111
} Koštejn, M.; Veselý, M.; Čada, M.; Topka, P.; Pokorná, D.; Hubička, Z.; et al. Modification of Cobalt Oxide Electrochemically Deposited on Stainless Steel Meshes with Co-Mn Thin Films Prepared by Magnetron Sputtering: Effect of Preparation Method and Application to Ethanol Oxidation. Catalysts 2021, 11, 1453. https://doi.org/10.3390/ catal11121453

Academic Editors: Pengyi Tang, Maria Chiara Spadaro and Jerome Vernieres

Received: 15 November 2021 Accepted: 25 November 2021 Published: 29 November 2021

Publisher's Note: MDPI stays neutral with regard to jurisdictional claims in published maps and institutional affiliations.

Copyright: (C) 2021 by the authors. Licensee MDPI, Basel, Switzerland. This article is an open access article distributed under the terms and conditions of the Creative Commons Attribution (CC BY) license (https:/ / creativecommons.org/licenses/by/ $4.0 /)$.

\begin{abstract}
Magnetron sputtering is an advantageous method for preparing catalysts supported on stainless steel meshes. Such catalysts are particularly suitable for processes carried out at high space velocities. One of these is the catalytic total oxidation of volatile organic compounds (VOC), economically feasible and environmentally friendly method of VOC abatement. The reactive radio frequency (RF) magnetron sputtering of $\mathrm{Mn}$ and $\mathrm{Co}+\mathrm{Mn}$ mixtures in an oxidation $\mathrm{Ar}+\mathrm{O}_{2}$ atmosphere was applied to form additional thin oxide coatings on cobalt oxide layers prepared by electrochemical deposition and heating on stainless steel meshes. Time of the RF magnetron sputtering was changed to obtain $\mathrm{MnO}_{\mathrm{x}}$ and $\mathrm{CoMnO}_{\mathrm{x}}$ coatings of various thickness $(0.1-0.3 \mu \mathrm{m})$. The properties of the supported $\mathrm{CoO}_{x}-\mathrm{MnO}_{x}$ and $\mathrm{CoO}_{x}-\mathrm{CoMnO}_{x}$ catalysts were characterized by scanning electron microscopy (SEM), powder X-ray diffraction (XRD), temperature programmed reduction $\left(\mathrm{H}_{2}-\mathrm{TPR}\right)$, Fourier-transform infrared (FTIR) and Raman spectroscopy, and X-ray photoelectron spectroscopy (XPS). The catalytic activity was investigated in the deep oxidation of ethanol, which was employed as a model VOC. According to the specific activities (amount of ethanol converted per unit mass of metal oxides per hour), the performance of $\mathrm{CoO}_{x}-\mathrm{MnO}_{\mathrm{x}}$ catalysts was higher than that of $\mathrm{CoO}_{\mathrm{x}}-\mathrm{CoMnO}_{\mathrm{x}}$ ones. The catalysts with the smallest layer thickness $(0.1 \mu \mathrm{m})$ showed the highest catalytic activity. Compared to the commercial pelletized Co-Mn-Al mixed oxide catalyst, the sputtered catalysts exhibited considerably higher (23-87 times) catalytic activity despite the more than 360-570 times lower content of the Co and Mn active components in the catalytic bed.
\end{abstract}

Keywords: magnetron sputtering; thin film; cobalt-manganese oxides; stainless steel meshes; VOC oxidation

\section{Introduction}

Due to the toxic, narcotic or carcinogenic properties of volatile organic compounds (VOCs), their emissions in industrial gases are a serious environmental problem. VOCs can also react with nitrogen oxides and oxygen to form harmful ozone. The concentration of these pollutants in the air can be reduced by catalytic total oxidation to carbon dioxide and water as final products; this process is significantly more energy efficient than the removal of VOCs by thermal combustion. Catalytic total oxidation is an effective process for minimizing the VOC emissions in industrial gases [1,2]. 
Precious metals $(\mathrm{Pt}, \mathrm{Pd})$ are highly active in the VOC oxidation. However, transition metal oxides also exhibit high catalytic activity in various oxidation reactions, e.g., oxidation of carbohydrates, alcohols, and aldehydes. Transition metal oxides catalysts are usually produced in the form of pellets or extrudates, which, however, exhibit a high pressure-drop of the catalyst bed. For this reason, monoliths or meshes are often used, in which a thin film of the active phase on the support allows its high utilization in catalytic reaction due to the low influence of internal diffusion of reactants and products. Structured catalysts in the form of meshes show a lower pressure drop of a catalytic bed than the packed bed of pelletized catalysts, which is especially advantageous for applications with high space velocities as, e.g., VOC oxidation [3].

We have studied formation of various cobalt-containing precursors on metal meshes; the supported catalysts with active oxide coatings were then obtained after the calcination of the deposited precursors [4]. Hydrothermal treatment of anodized aluminum meshes in aqueous solution containing $\mathrm{Co}$ and $\mathrm{Mn}$ nitrates resulted in the crystallization of $\mathrm{Co}-\mathrm{Mn}-\mathrm{Al}$ layered double hydroxides on the mesh surface. After calcination, the supported Co-Mn-Al mixed oxide catalysts were applied in the abatement of volatile organic compounds, namely ethanol, which is often emitted from pharmaceutical plants and printing works and widely used as a biofuel. Although the structured catalysts had nearly 50 times lower content of the active components, they showed approximately the same catalytic activity as the pelletized catalyst from commercial $\mathrm{Co}_{3} \mathrm{O}_{4}$. However, adhesion of the layers to the substrate was not satisfactory [4].

In the following studies, we replaced the aluminum meshes with mechanically more stable stainless steel ones. The precipitation of $\mathrm{Co}$ and $\mathrm{Mn}$ nitrates in the presence of hydrolyzing urea under hydrothermal conditions allowed the crystallization of $\mathrm{Co}$ and Mn carbonate precursors preferentially on the stainless steel surface and the formation of relatively well adherent coatings. Clearly, the surface corrosion of stainless steel observed during urea hydrolysis in aqueous solutions increased the roughness of the initially smooth surface and facilitated the precipitation of precursors on the supports [5].

Another option to improve the adhesion of transition metal oxides to stainless steel meshes is the use of the plasma enhanced physical vapor deposition (PVD). We used radiofrequency (RF) magnetron sputtering in the oxidation $\mathrm{Ar}+\mathrm{O}_{2}$ atmosphere for coating the stainless steel meshes with thin $\mathrm{Co}_{3} \mathrm{O}_{4}$ films. The meshes coated with thin $\mathrm{Co}_{3} \mathrm{O}_{4}$ film were then used as substrates for electrochemical deposition (ED) of cobalt hydroxide precursors formed on the mesh surface due to $\mathrm{pH}$ increase during cathodic reduction of cobalt nitrate in aqueous solution; the deposited cobalt hydroxide precursors were finally transformed to $\mathrm{Co}_{3} \mathrm{O}_{4}$ by calcination at $500^{\circ} \mathrm{C}$ in air. The rather poor adhesion of the $\mathrm{Co}_{3} \mathrm{O}_{4}$ layer prepared by electrochemical deposition was significantly improved when the catalysts were coated with additional cobalt oxide thin film by magnetron sputtering. Weight loss of active oxide layer found for the RF-ED-RF catalyst after treatment in an ultrasonic bath was only 1\% [6].

As the Co-Mn oxides are more active in the oxidation of organic compounds than the Co ones [7], we decided to apply the plasma sputtering of $\mathrm{Mn}$ and Co-Mn oxides as the final coating on the $\mathrm{Co}_{3} \mathrm{O}_{4}$ formed by the electrochemical deposition and calcination. Cai et al. [8] demonstrated that the introduction of $\mathrm{Mn}$ into $\mathrm{CoO}_{\mathrm{x}}$ led to an increase in the surface concentration of $\mathrm{Co}^{2+}$ and formation of active oxygen, which contributed to the high catalytic activity in the VOC oxidation. In a recent study of Zhang et al. [9], the introduction of Mn enhanced the reducibility and catalytic performance of cobalt oxides. The Co-Mn oxide catalysts were more active in toluene oxidation than their Co-Ni or $\mathrm{Co}-\mathrm{Cu}$ analogues. However, the structured Co-Mn catalysts prepared by plasma sputtering supported on stainless steel meshes have not yet been studied.

Therefore, this work was focused on the preparation of structured Co-Mn mixed oxide catalysts supported on stainless steel meshes using combination of electrochemical deposition and plasma sputtering. The physical-chemical properties of the prepared catalysts were investigated by XRD, SEM, FTIR and Raman spectroscopy, $\mathrm{H}_{2}$-TPR, and XPS. The catalytic activity of the catalysts was examined in the total oxidation of ethanol, which 
was employed as a model compound of volatile organic compound. The obtained physicalchemical characteristics were correlated with the activity and selectivity of the catalysts. The properties of the catalysts were compared with those of the pelletized commercial Co-Mn-Al mixed oxide catalyst (Astin 2-100, ASTIN Catalysts and Chemicals, s.r.o., 43601 Litvínov-Záluží, Czech Republic).

\section{Results}

\subsection{Content of Active Co and Mn Components}

Table 1 shows the average weight increase after each deposition procedure. A first coating in the amount of $0.10-0.16 \mathrm{wt} . \%$ was performed by RF magnetron sputtering of $\mathrm{Co}$ in oxidation $\mathrm{Ar}+\mathrm{O}_{2}$ atmosphere, when cobalt oxide (very likely $\mathrm{Co}_{3} \mathrm{O}_{4}$ ) was formed. The stainless steel meshes coated with the cobalt oxide thin film were used as substrate for the electrochemical deposition, when a cobalt hydroxide layer was formed on the surface. After the electrochemical deposition, the samples were calcined at $500{ }^{\circ} \mathrm{C}$ in air and the hydroxide precursor was transformed to $\mathrm{Co}_{3} \mathrm{O}_{4}$. The amount of the second $\mathrm{Co}_{3} \mathrm{O}_{4}$ layer obtained from the electrochemically deposited precursor ranged from 0.20 to $0.40 \mathrm{wt} . \%$; after calcination, the two deposited cobalt oxide layers contained in total $0.32-0.56 \mathrm{wt} . \%$ of $\mathrm{Co}_{3} \mathrm{O}_{4}$. After that, small amounts of $\mathrm{Mn}$ or $\mathrm{Co}-\mathrm{Mn}$ oxides were deposited on the samples by additional RF magnetron sputtering of $\mathrm{Mn}$ or $\mathrm{Co}$ and $\mathrm{Mn}$ in the oxidation atmosphere. The conditions during the simultaneous $\mathrm{Co}$ and $\mathrm{Mn}$ magnetron sputtering were chosen to obtain a Co-Mn oxide coating with Co:Mn molar ratio of 1:1. Finally, the samples were calcined again at $500{ }^{\circ} \mathrm{C}$ in air. Amount of the third layer of $\mathrm{MnO}_{x}$ or $\mathrm{CoMnO}_{\mathrm{x}}$ gradually increased from 0.05 to $0.15 \mathrm{wt} . \%$ depending on the deposition time, which affected the layer thickness. In total, the supported catalysts contained $0.45-0.75 \mathrm{wt} . \%$ of metal oxides $\left(\mathrm{MeO}_{\mathrm{x}}\right)$ deposited on the meshes.

Table 1. Average amount of each layer in the catalysts (per piece of a stainless steel mesh, related to the weight of sample corresponding to a given preparation phase).

\begin{tabular}{|c|c|c|c|c|c|c|}
\hline Catalyst & Substrate, $g$ & $\begin{array}{c}\mathrm{CoO} \times \mathrm{RF}^{\mathrm{a}} \\
\text { wt. } \%\end{array}$ & $\begin{array}{c}\mathrm{CoO} \times \mathrm{ED}^{\mathrm{b}} \\
\text { wt. } \%\end{array}$ & $\begin{array}{c}\text { MnOx } \\
\text { (CoMnOx) } \\
\text { RF, wt. } \%\end{array}$ & $\begin{array}{c}\mathrm{MeOx}^{\mathrm{c}} \\
\text { wt. } \%\end{array}$ & $\begin{array}{c}\text { Weight } \\
\text { Loss of } \\
\mathrm{MeO}_{\mathrm{x}}{ }^{\mathrm{d}} \\
\%^{\prime}\end{array}$ \\
\hline $\mathrm{MnO}_{\mathrm{x}}-2$ & 0.46700 & 0 & 0 & 0.48 & 0.48 & 90 \\
\hline $\mathrm{MnO}_{\mathrm{x}}-0.1$ & 0.46108 & 0.15 & 0.35 & 0.06 & 0.56 & 22 \\
\hline $\mathrm{MnO}_{\mathrm{x}}-0.2$ & 0.46089 & 0.16 & 0.40 & 0.11 & 0.67 & 37 \\
\hline $\mathrm{MnO}_{\mathrm{x}}-0.3$ & 0.47139 & 0.16 & 0.33 & 0.15 & 0.64 & 39 \\
\hline $\mathrm{CoMnO}_{\mathrm{x}}-0.1$ & 0.47035 & 0.15 & 0.21 & $(0.05)$ & 0.41 & 28 \\
\hline $\mathrm{CoMnO}_{\mathrm{x}}-0.2$ & 0.46513 & 0.16 & 0.20 & $(0.09)$ & 0.45 & 21 \\
\hline $\mathrm{CoMnO}_{\mathrm{x}}-0.3$ & 0.46602 & 0.10 & 0.22 & $(0.14)$ & 0.46 & 25 \\
\hline $\mathrm{CoO}_{x}-2$ & 0.46704 & 0.75 & 0 & 0 & 0.75 & 0 \\
\hline
\end{tabular}

a Radio frequency magnetron sputtering. ${ }^{\mathrm{b}}$ Electrochemical deposition. ${ }^{\mathrm{c}}$ Content of metal oxides after calcination.

$\mathrm{d}$ The weight loss after $10 \mathrm{~min}$ treatment in an ultrasonic bath related to the weight of deposited metal oxides.

Due to the very low Co and Mn content in the supported catalysts and the simultaneous presence of $\mathrm{Mn}$ in the used stainless steel meshes, it was not possible to determine the composition of the catalysts by chemical analysis. In order to calculate the $\mathrm{Co} /(\mathrm{Co}+\mathrm{Mn})$ molar ratios in the prepared catalysts, the powders obtained by mechanical abrasion of the catalysts were analyzed by EDX (Table 2$)$. The $\mathrm{Co} /(\mathrm{Co}+\mathrm{Mn})_{\mathrm{EDX}}$ ratio decreased slightly with increasing thickness of the $\mathrm{MnO}_{\mathrm{x}}$ and $\mathrm{CoMnO}_{\mathrm{x}}$ layers on the meshes.

\subsection{Powder $X R D$}

Powder XRD patterns of the prepared catalysts are shown in Figure 1. Sharp diffraction peaks with high intensity at approximately $51^{\circ}$ and $59^{\circ} 2 \theta$ correspond to iron (PDF 04-014-0264) or various iron-containing alloys such as $\mathrm{Fe}_{0.65} \mathrm{Cr}_{0.1} \mathrm{Ni}_{0.25}$ (PDF 04-019-2390); therefore, these peaks were attributed to the stainless steel support. The $\mathrm{CoO}_{\mathrm{x}}-2$ catalyst, which was prepared using long-term RF magnetron sputtering and then calcined at $500{ }^{\circ} \mathrm{C}$ in air, contained diffraction peaks corresponding to $\mathrm{Co}_{3} \mathrm{O}_{4}$ with a spinel structure (PDF 
01-086-8289). No crystalline oxide phase was detected in the powder XRD pattern of the $\mathrm{MnO}_{\mathrm{x}}-2$ catalyst. The catalysts, combining cobalt oxide layers deposited by $\mathrm{RF}$ magnetron sputtering and electrochemical deposition with additional $\mathrm{MnO}_{\mathrm{x}}$ or $\mathrm{CoMnO}_{\mathrm{x}}$ coatings, exhibited diffraction peaks characteristic of mixed Co-Mn oxides with spinel structure and relatively low $\mathrm{Mn}$ content, such as $\mathrm{Co}_{2.8} \mathrm{Mn}_{0.2} \mathrm{O}_{4}$ (PDF 01-084-4036) and $\mathrm{Co}_{2.7} \mathrm{Mn}_{0.3} \mathrm{O}_{4}$ (PDF 01-084-4037). The decreased baseline observed in the powder XRD patterns up to approximately $40^{\circ} 2 \theta$ could be connected with presence of an XRD-amorphous part in the prepared samples.

Table 2. Composition, surface area of the prepared catalysts, lattice parameters, and crystallite sizes of spinel-type oxides.

\begin{tabular}{|c|c|c|c|c|c|c|c|}
\hline Catalyst & $\begin{array}{l}\text { Co }^{a} \\
\text { at. } \%\end{array}$ & $\begin{array}{l}\text { Mn }^{a} \\
\text { at. } \%\end{array}$ & $\begin{array}{c}\mathrm{Co} / \\
(\mathrm{Co}+\mathrm{Mn})_{\mathrm{EDX}} \\
\mathrm{mol} \mathrm{mol}^{-1}\end{array}$ & $\begin{array}{c}\text { Surface } \\
\text { Area } \\
\mathrm{m}^{2} \\
\mathrm{~g}_{\text {cat }}-1\end{array}$ & $\begin{array}{c}\text { Surface } \\
\text { Area } \\
\text { m }^{2} \\
\text { goxide }^{-1}\end{array}$ & $\begin{array}{c}\text { Lattice } \\
\text { Parameter } \\
\text { nm }\end{array}$ & $\begin{array}{c}\text { Crystallite } \\
\text { Size } \\
\text { nm }\end{array}$ \\
\hline $\mathrm{MnO}_{\mathrm{x}}-2$ & - & - & $0^{\mathrm{b}}$ & 0.12 & 25.0 & n.d. & n.d. \\
\hline $\mathrm{MnO}_{\mathrm{x}}-0.1$ & 36.04 & 2.47 & 0.88 & 0.11 & 19.6 & 0.8123 & 15.7 \\
\hline $\mathrm{MnO}_{x}-0.2$ & 28.27 & 9.67 & 0.82 & 0.11 & 16.4 & 0.8118 & 17.1 \\
\hline $\mathrm{MnO}_{\mathrm{x}}-0.3$ & 13.61 & 4.3 & 0.74 & 0.13 & 20.3 & 0.8114 & 5.1 \\
\hline $\mathrm{CoMnO}_{\mathrm{x}}-0.1$ & 23.43 & 2.38 & 0.86 & 0.06 & 13.3 & 0.8132 & 13.3 \\
\hline $\mathrm{CoMnO}_{\mathrm{x}}-0.2$ & 46.18 & 1.97 & 0.85 & 0.08 & 17.8 & 0.8138 & 5.9 \\
\hline $\mathrm{CoMnO}_{\mathrm{x}}-0.3$ & 15.29 & 3.78 & 0.67 & 0.07 & 15.2 & 0.8125 & 7.3 \\
\hline $\mathrm{CoO}_{x-2}$ & - & - & $1^{b}$ & 0.04 & 5.3 & 0.8083 & 37.6 \\
\hline $\operatorname{Com}^{a, b, c}$ & 61.5 & 14.0 & 0.80 & 85 & 115 & n.d. & n.d. \\
\hline
\end{tabular}

${ }^{\mathrm{a}}$ Determined by EDX. ${ }^{\mathrm{b}}$ Based on chemical composition. ${ }^{\mathrm{c}}$ Pelletized commercial Co-Mn-Al mixed oxide catalyst. n.d.-Not determined.

The spinel lattice parameters were calculated as the average value of all the diffraction peaks found. The spinel phases detected in the structured catalysts showed slightly larger lattice parameters compared to the $\mathrm{Co}_{3} \mathrm{O}_{4}$ found in the $\mathrm{CoO}_{\mathrm{x}}-2$ sample (Table 2). The mean coherence lengths evaluated from the powder XRD data reflected the ordering of the structure of the crystalline phases and can be considered as approximate crystallite sizes. The integral width values $\left(B_{o b s}\right)$ were automatically determined by HighScore Plus software once the powder XRD patterns were subjected to standard profile fitting. The next step involved calculating the crystallite sizes using the Scherrer equation, taking into account the integral width values of each diffraction peak. The largest crystallite sizes were found for the $\mathrm{CoO}_{x}-2$ sample. The spinel phases in the structured catalysts showed significantly smaller crystallite sizes (Table 2). This could be related to the interaction between the $\mathrm{Co}_{3} \mathrm{O}_{4}$ obtained by calcination from the precursor formed during the electrochemical deposition and the Mn-containing oxide coatings deposited later by RF magnetron sputtering. This interaction could also explain the observed slight change in the lattice parameters of the spinel.

A different composition was reported for the Co-Mn oxides prepared by other methods. For example, heating of carbonate precursors, formed on stainless steel meshes during their treatment in aqueous solutions of $\mathrm{Co}$ and $\mathrm{Mn}$ nitrates and urea under hydrothermal conditions, resulted in an incorporation of $\mathrm{Mn}$ cations into $\mathrm{Co}_{3} \mathrm{O}_{4}$ spinel lattice or direct $\mathrm{CoMnO}_{3}$ formation in the samples with lower Mn content. The catalyst with relatively low $\mathrm{Mn}$ content contained $\mathrm{Co}_{3} \mathrm{O}_{4}$ together with a cubic Co-Mn mixed oxide corresponding to $\mathrm{Mn}_{1.9} \mathrm{Co}_{1.1} \mathrm{O}_{4}$ with spinel structure [10]. Tang et al. [11] prepared the $(\mathrm{Co}, \mathrm{Mn})(\mathrm{Mn}, \mathrm{Co})_{2} \mathrm{O}_{4}$ oxide by decomposition of oxalates. Other authors reported mixture of tetragonal $\mathrm{Mn}_{2} \mathrm{CoO}_{4}$ and cubic $\mathrm{MnCo}_{2} \mathrm{O}_{4}$ oxides prepared applying ball milling [12] or sol-gel combustion method [13]. Difference in the phase compositions of the obtained oxides could be caused by thermal treatment; the aforementioned authors used higher temperatures and longer times during thermal treatment, resulting in the formation of other oxide phases. 


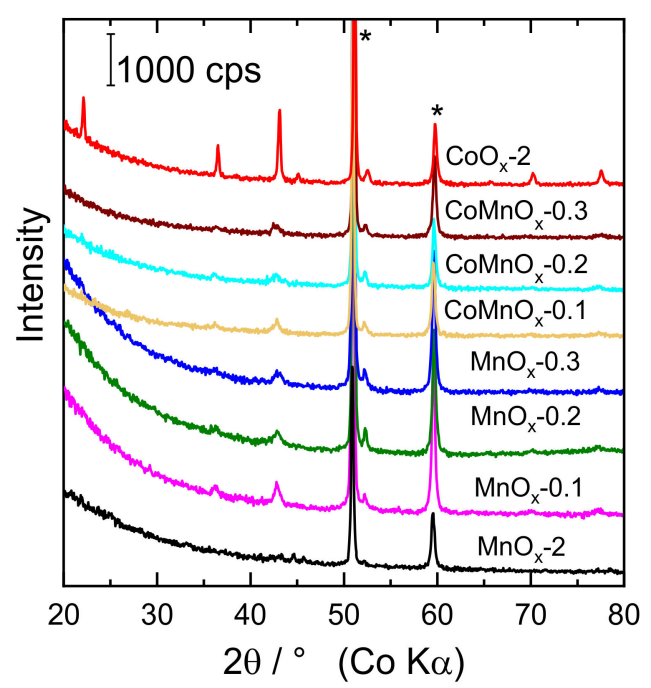

Figure 1. Powder XRD patterns of the catalysts calcined $4 \mathrm{~h}$ at $500{ }^{\circ} \mathrm{C}\left({ }^{*}\right.$ - stainless steel support).

Powder XRD pattern of the commercial catalyst (the Com sample) is shown in the Supplementary Materials (Figure S1). The fresh pelletized Com catalyst contained Co-MnAl mixed oxide with spinel structure. A diffraction peak corresponding to graphite was also detected in the powder XRD pattern as a slight amount of graphite ( $3 \mathrm{wt} . \%$ ) was added to the mixed oxide precursor before pelletizing.

\subsection{Morphology of the Co and Mn Oxides Coatings}

In general, the method used for the preparation of the active phase may influence the size and morphology of the prepared products. For example, the formation of urchin-like hierarchical $\mathrm{CoMn}_{2} \mathrm{O}_{4}$ nanostructures [14], pseudospheric $\mathrm{Co}_{3} \mathrm{O}_{4}$ particles, and $\mathrm{Mn}_{\mathrm{x}} \mathrm{Co}_{3-\mathrm{x}} \mathrm{O}_{4}$ core-shell nanoparticles [15] was reported.

The surface morphology of the investigated catalysts is documented by the SEM images in Figure 2. The RF magnetron sputtering of $\mathrm{Mn}$ in an oxidizing atmosphere (the $\mathrm{MnO}_{\mathrm{x}}-2$ sample) resulted in the formation of relatively large particles with a thin platelet morphology; the second generation of small crystals growing on the platelets is clearly visible, resulting in a complex oxide coating structure in the $\mathrm{MnO}_{\mathrm{x}}-2$ catalyst. The $\mathrm{RF}$ magnetron sputtering of $2 \mu \mathrm{m}$ thick cobalt oxide thin film (sample $\mathrm{CoO}_{\mathrm{x}}-2$ ) resulted in smaller but thicker platelets with tight packing and nearly perpendicular orientation to the support. The very different morphology of the $\mathrm{MnO}_{x}-2$ and $\mathrm{CoO}_{x}-2$ catalysts can be clearly seen in the SEM images showing the oxide layer profiles (Figure 3).

The $\mathrm{CoO}_{\mathrm{x}}$-RF-ED sample (the cobalt oxide layer before additional RF magnetron sputtering of $\mathrm{MnO}_{\mathrm{x}}$ or $\mathrm{CoMnO}_{\mathrm{x}}$ ) also showed small platelet crystals with an almost perpendicular orientation to the support (Figure 2). SEM images of $\mathrm{MnO}_{\mathrm{x}}-0.1, \mathrm{MnO}_{\mathrm{x}}-0.2$, and $\mathrm{MnO}_{\mathrm{x}}-0.3$ catalysts with increasing amounts of $\mathrm{MnO}_{\mathrm{x}}$ deposited on $\mathrm{Co}_{3} \mathrm{O}_{4}$ layers showed a complex morphology of deposited oxide coatings analogous to that of the $\mathrm{MnO}_{\mathrm{x}}-2$ catalyst. A similar morphology was also observed in the SEM images of $\mathrm{CoMnO}_{x}-0.1, \mathrm{CoMnO}_{\mathrm{x}}-0.2$, and $\mathrm{CoMnO}_{\mathrm{x}}-0.3$ catalysts. The formation of $\mathrm{Co}-\mathrm{Mn}$ oxide can be expected when $\mathrm{Co}$ and $\mathrm{Mn}$ are simultaneously deposited on $\mathrm{Co}_{3} \mathrm{O}_{4}$ layers by $\mathrm{RF}$ magnetron sputtering in an oxidizing atmosphere. Very likely, tiny crystals of $\mathrm{MnO}_{\mathrm{x}}$ and $\mathrm{CoMnO}_{\mathrm{x}}$ oxides were formed during the additional RF magnetron sputtering, which gradually covered the cobalt oxide platelets; in Figure 2, the increasing size of tiny crystals of $\mathrm{MnO}_{\mathrm{x}}$ and $\mathrm{CoMnO}_{\mathrm{x}}$ on the $\mathrm{Co}_{3} \mathrm{O}_{4}$ platelets can be observed with increasing deposition time. The images of the oxide layer profiles (Figure 3 ) show the complex morphology of oxide layers in the supported $\mathrm{CoO}_{x}-\mathrm{MnO}_{\mathrm{x}}$ and $\mathrm{CoO}_{\mathrm{x}}-\mathrm{CoMnO}_{\mathrm{x}}$ catalysts with small crystals grown during the additional $\mathrm{RF}$ magnetron sputtering on $\mathrm{Co}_{3} \mathrm{O}_{4}$ platelets. As for the possible heterogeneity of the samples, the thicknesses of $\mathrm{RF}$ sputtered $\mathrm{MnO}_{\mathrm{x}}$ and $\mathrm{CoMnO}_{\mathrm{x}}$ thin films were $0.1,0.2$, and 
$0.3 \mu \mathrm{m}$. The generally accepted theory is that a thin layer formed by evaporation or sputtering typically starts in the form of islands that later coalesce into a continuous thin layer as other particles come from a source. We believe that the thickness of prepared RF thin films is high enough that on the ED coating a continuous thin film is formed. This statement is further supported by SEM images of the pure ED coating (Figure 2, top left photo), which can be compared with samples of ED coatings covered with RF sputtered thin film (Figure 2, photos on the second and third row). We clearly see that porous morphology of ED coating surface is more or less preserved when the RF thin film is applied (we can observe that pores in the ED coating are partly filled with the RF thin film). Moreover, the SEM images do not show any island structure, even for pure RF deposited thin films (Figure 2, the first row, middle and right photos). The RF thin films were first deposited on a Si wafer to estimate thin film thickens and consequently required deposition time, when meshes were finally deposited. No island structure was observed on such Si wafers.

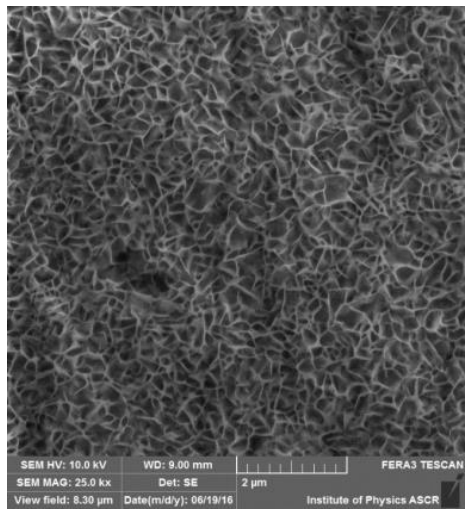

(RF-ED sample *)

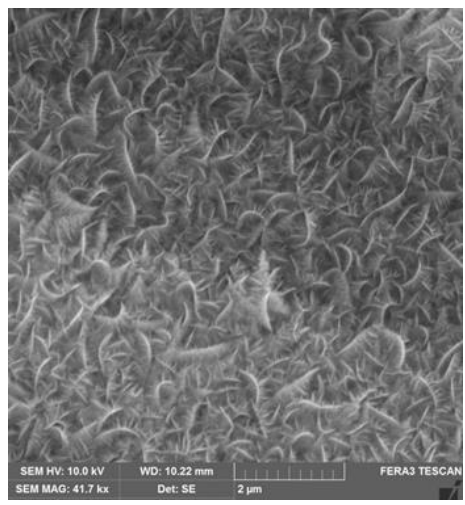

(MnOx-0.1)

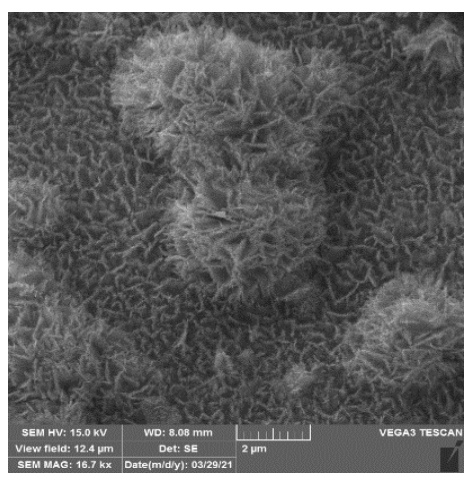

$\left(\mathrm{CoMnO}_{x}-0.1\right)$

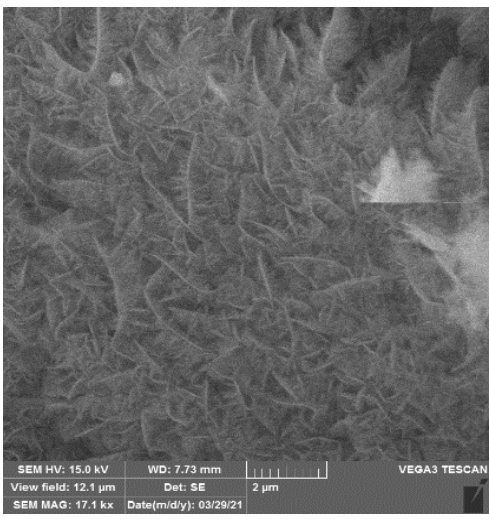

$\left(\mathrm{MnO}_{\mathrm{x}}-2\right)$

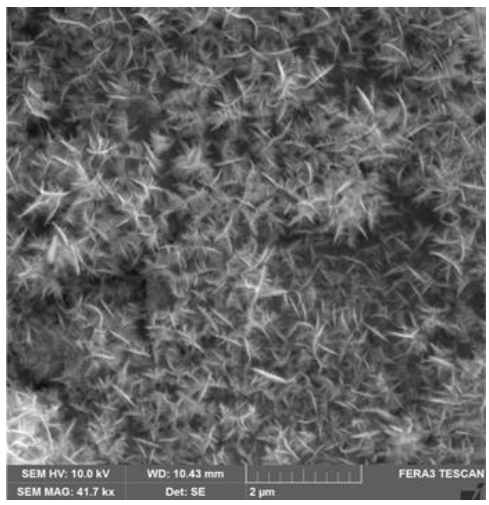

$\left(\mathrm{MnO}_{\mathrm{x}}-0.2\right)$

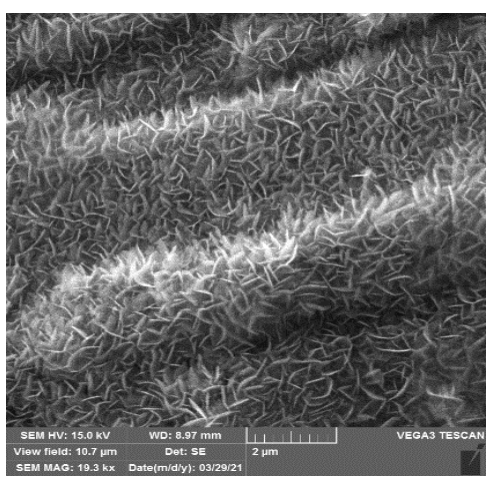

(CoMnOx-0.2)

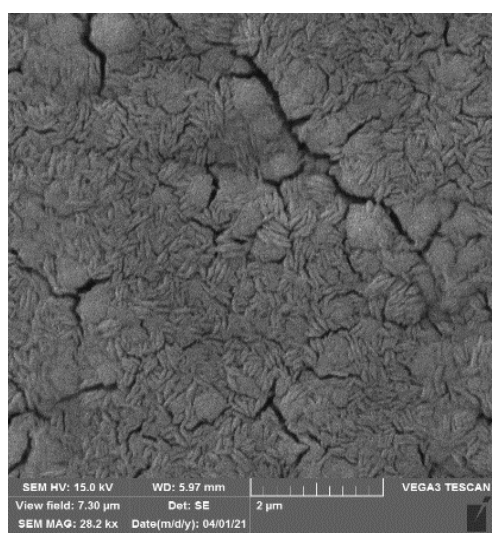

$\left(\mathrm{CoO}_{x}-2\right)$

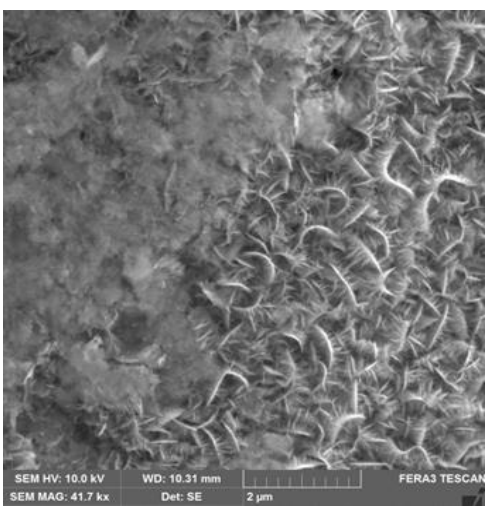

$\left(\mathrm{MnO}_{\mathrm{x}}-0.3\right)$

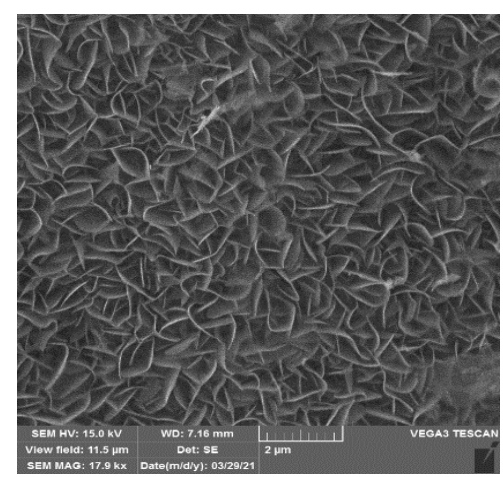

(CoMnOx-0.3)

Figure 2. Surface morphology of the oxide layers deposited on the stainless steel supports ( ${ }^{*}$ the RF-ED sample with cobalt oxide layer before additional RF magnetron sputtering of $\mathrm{MnO}_{\mathrm{x}}$ or $\mathrm{CoMnO}_{\mathrm{x}}$ ). 


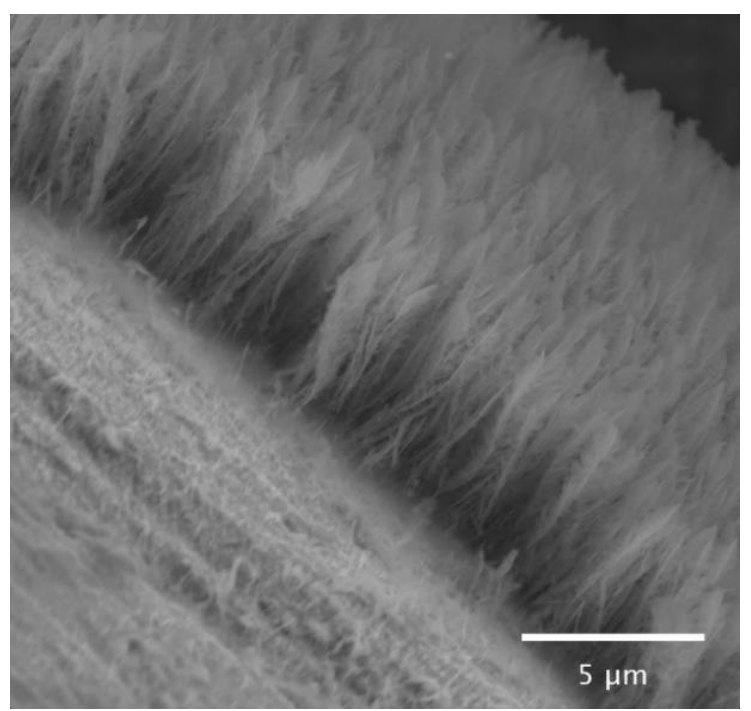

$\left(\mathrm{MnO}_{\mathrm{x}}-2\right)$

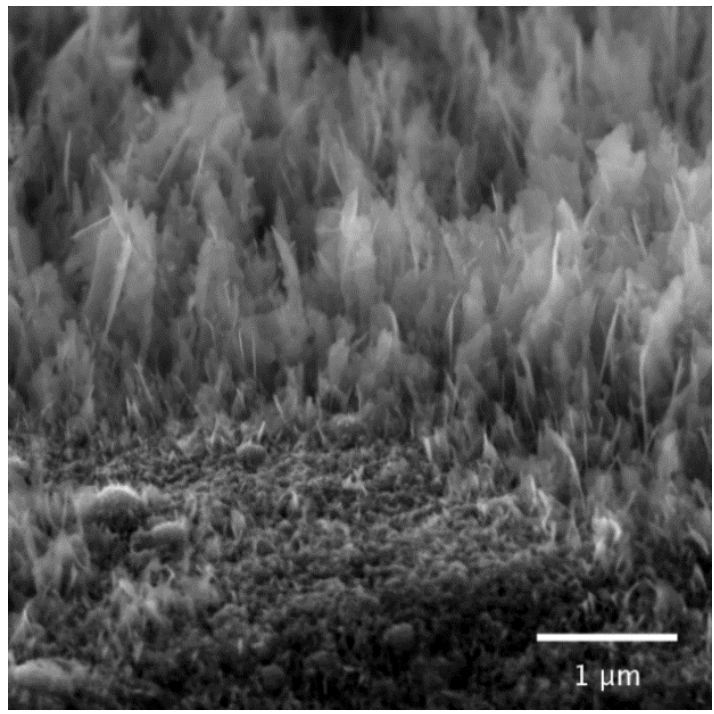

$\left(\mathrm{MnO}_{\mathrm{x}}-0.3\right)$

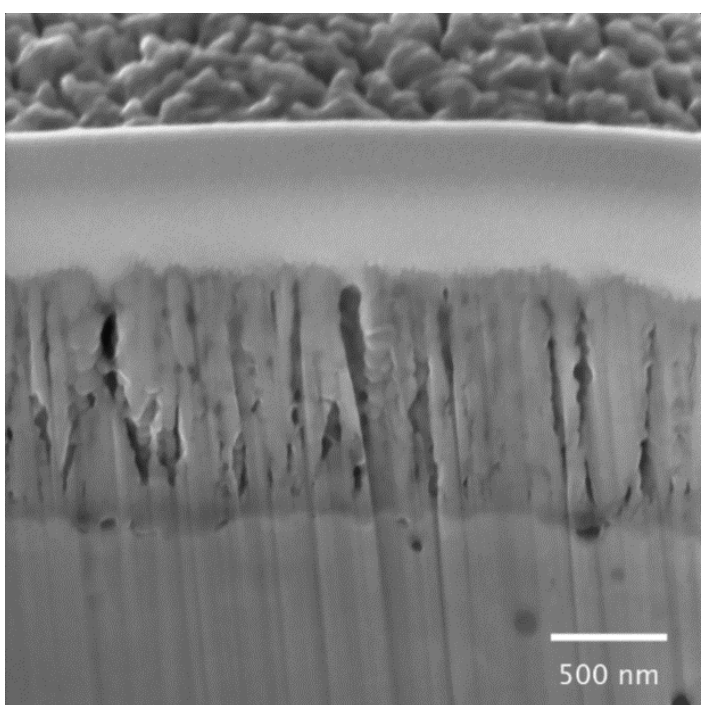

$(\mathrm{CoO}-2)$

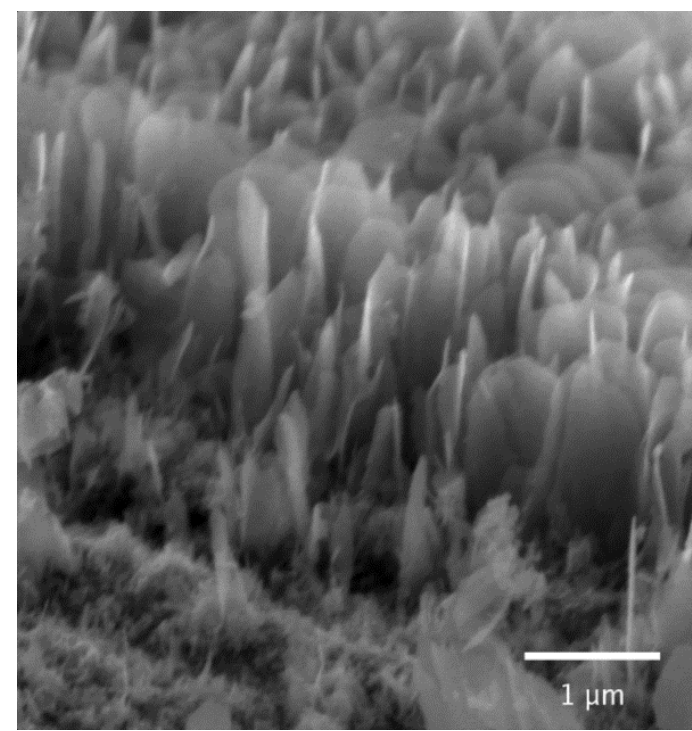

$\left(\mathrm{CoMnO}_{\mathrm{x}}-0.3\right)$

Figure 3. Profiles of the oxide layers deposited on stainless steel supports.

The adhesion of the deposited oxide layers to the stainless steel support may be related to the size and morphology of the metal oxide particles. The adhesion was investigated by a simple test involving treatment of the catalysts immersed in acetone in an ultrasonic bath for $10 \mathrm{~min}$. After drying, the weight loss was determined and related to the initial weight of the oxides in the catalysts. The values obtained are summarized in Table 1. The weight losses ranged from 0 to $90 \%$; the highest value was found for the $\mathrm{MnO}_{\mathrm{x}}-2$ catalyst and the lowest for the $\mathrm{CoO}_{x}-2$ catalyst, for which no weight loss was observed. Recently, we found that the relatively poor adhesion of cobalt oxide layers prepared by electrochemical deposition on stainless steel meshes coated with thin layers of $\mathrm{Co}_{3} \mathrm{O}_{4}$ was significantly improved when the catalysts were coated with an additional thin layer of $\mathrm{Co}_{3} \mathrm{O}_{4}$ by magnetron sputtering [6]. The RF magnetron sputtering carried out to cover the cobalt oxide layer with additional $\mathrm{MnO}_{\mathrm{x}}$ or $\mathrm{CoMnO}_{\mathrm{x}}$ coatings did not lead to such an enhancement effect; for the $\mathrm{CoO}_{\mathrm{x}}-\mathrm{MnO}_{\mathrm{x}}$ and $\mathrm{CoO}_{\mathrm{x}}-\mathrm{CoMnO}_{\mathrm{x}}$ catalysts, weight loss ranging from 21 to 39 wt.\% of deposited oxides was observed (Table 1). In the case of 
magnetron sputtering of $\mathrm{Mn}$, lower adhesion of oxide layers was observed compared to $\mathrm{Co}+\mathrm{Mn}$. The $\mathrm{MnO}_{\mathrm{x}}$ and $\mathrm{CoMnO}_{\mathrm{x}}$ coatings formed by small crystals grown on the cobalt oxide platelets during additional magnetron sputtering (Figures 2 and 3) were probably unable to significantly strengthen the cobalt oxide layer formed by the previous electrochemical deposition.

All supported catalysts exhibited low surface areas ranging from 0.04 to $0.13 \mathrm{~m}^{2} \mathrm{~g}^{-1}$ (calculated per gram of catalyst, i.e., including stainless steel meshes, Table 2). The surface area relative to the weight of oxides deposited on stainless steel meshes was ranging from 13 to $25 \mathrm{~m}^{2} \mathrm{~g}^{-1}$ (Table 2), except for the $\mathrm{CoO}_{\mathrm{x}}-2$ sample. The low surface area of the cobalt oxide in the $\mathrm{CoO}_{\mathrm{x}}-2$ sample $\left(5 \mathrm{~m}^{2} \mathrm{~g}^{-1}\right)$ was probably related to the close packing of the thicker particles observed in the SEM images (Figures 2 and 3). The pelletized commercial Co-Mn-Al mixed oxide (the Com catalyst) showed a much larger surface area of $115 \mathrm{~m}^{2} \mathrm{~g}^{-1}$.

\section{4. $\mathrm{H}_{2}-T P R$}

The results of temperature-programmed reduction $\left(\mathrm{H}_{2}\right.$-TPR) by hydrogen obtained in the temperature range from 25 to $900{ }^{\circ} \mathrm{C}$ are shown in Figure 3 and the quantitative data are summarized in Table 3. The maximum in the profiles corresponds to the maximum of the reduction rate, and the shift of the temperature maximum indicates a change in the metal-oxygen bond strength [16]. The TPR profiles (Figure 4) reflected the different contents of $\mathrm{Co}$ and $\mathrm{Mn}$ in the catalysts. The $\mathrm{CoO}_{x}-2$ catalyst showed one main reduction peak with $\mathrm{T}_{\max }$ at $388^{\circ} \mathrm{C}$. This peak was attributed to the unresolved reduction of $\mathrm{Co}^{3+}$ to $\mathrm{Co}^{2+}$ and $\mathrm{Co}^{2+}$ to $\mathrm{Co}^{0}[17,18]$. The reduction of the $\mathrm{MnO}_{\mathrm{x}}-2$ catalyst containing only $\mathrm{Mn}$ oxides proceeded in three steps with temperature maxima at 325,388 , and $480{ }^{\circ} \mathrm{C}$. The reduction process included $\mathrm{Mn}_{3} \mathrm{O}_{4}$ as an intermediate; the reduction of $\mathrm{MnO}_{2} / \mathrm{Mn}_{2} \mathrm{O}_{3}$ to $\mathrm{Mn}_{3} \mathrm{O}_{4}$ and the subsequent reduction of $\mathrm{Mn}_{3} \mathrm{O}_{4}$ to $\mathrm{MnO}$ have been described $[19,20]$. The reduction of $\mathrm{MnO}_{2} / \mathrm{Mn}_{2} \mathrm{O}_{3}$ can proceed in one step without the formation of the $\mathrm{Mn}_{3} \mathrm{O}_{4}$ intermediate, depending on the conditions of the TPR experiment [21]. Recently, it has been reported that the reduction of $\mathrm{Co}-\mathrm{Mn}$ mixed oxides proceeds in two steps [22]. In the first step, $(\mathrm{Mn}, \mathrm{Co})_{3} \mathrm{O}_{4}$ is reduced to form solid solutions of $(\mathrm{Mn}, \mathrm{Co}) \mathrm{O} ; \mathrm{Co}_{2} \mathrm{MnO}_{4}$ starts to reduce first to $\mathrm{Co}_{0.6} \mathrm{Mn}_{0.4} \mathrm{O}$ and then $\mathrm{Mn}_{2} \mathrm{CoO}_{4}$ is converted to $\mathrm{Mn}_{0.6} \mathrm{Co}_{0.4} \mathrm{O}$. In the second step, solid solutions of $(\mathrm{Mn}, \mathrm{Co}) \mathrm{O}$ are reduced to metallic $\mathrm{Co}$ and $\mathrm{MnO}$. Similar behaviour can be observed for other Co-Mn oxide based catalysts.

Table 3. Characteristic parameters obtained from the temperature-programmed reduction measurements.

\begin{tabular}{|c|c|c|c|c|}
\hline Catalyst & $\begin{array}{c}\mathrm{MeOx}^{\mathrm{a}} \\
\text { wt. } \%\end{array}$ & $\begin{array}{c}\mathrm{H}_{2} \text { Consumption } \\
\left(20-500{ }^{\circ} \mathrm{C}\right) \\
\mathrm{mmol} \mathrm{H}_{2} \mathrm{~g}_{\text {cat }}{ }^{-1}\end{array}$ & $\begin{array}{l}\mathrm{H}_{2} \text { Consumption } \\
\quad\left(20-500^{\circ} \mathrm{C}\right) \\
{\text { mol } \mathrm{H}_{2} \text { mol }_{\text {oxides }}}^{-1}\end{array}$ & $\begin{array}{c}\mathbf{T}_{\max } \\
{ }^{\circ} \mathrm{C}\end{array}$ \\
\hline $\mathrm{MnO}_{\mathrm{x}}-2$ & 0.48 & 0.03 & 0.99 & $325 ; 388 ; 480$ \\
\hline $\mathrm{MnO}_{\mathrm{x}}-0.1$ & 0.56 & 0.08 & 3.33 & $397 ; 412 ; 447$ \\
\hline $\mathrm{MnO}_{\mathrm{x}}-0.2$ & 0.67 & 0.12 & 3.81 & $412 ; 447$ \\
\hline $\mathrm{MnO}_{\mathrm{x}}-0.3$ & 0.64 & 0.10 & 3.35 & 411 \\
\hline $\mathrm{CoMnO}_{\mathrm{x}}-0.1$ & 0.45 & 0.06 & 3.06 & $390 ; 412$ \\
\hline $\mathrm{CoMnO}_{\mathrm{x}}-0.2$ & 0.45 & 0.08 & 4.19 & $393 ; 411$ \\
\hline $\mathrm{CoMnO}_{\mathrm{x}}-0.3$ & 0.46 & 0.08 & 3.80 & $405 ; 436$ \\
\hline $\mathrm{CoO}_{x}-2$ & 0.75 & 0.13 & 4.17 & 388 \\
\hline Com ${ }^{b}$ & 75.5 & 3.90 & 1.13 & $278 ; 388 ; 682$ \\
\hline
\end{tabular}

a Content of metal oxides after calcination. ${ }^{\mathrm{b}}$ Pelletized commercial Co-Mn-Al mixed oxide catalyst.

The reduction progress of Co-Mn mixed oxides prepared by plasma sputtering reflected the reduction of both individual components. The broadening of the temperature range, in which the reduction of the catalysts took place reflected incorporation of $\mathrm{Mn}$ into cobalt oxide. For the thinnest $\mathrm{Mn}$ oxide addition layer $\left(\mathrm{MnO}_{\mathrm{x}}-0.1\right.$ catalyst), the TPR showed a very broad reduction peak between 380 and $510^{\circ} \mathrm{C}$ (with a shoulder at $397^{\circ} \mathrm{C}$ and peak maxima at 412 and $447^{\circ} \mathrm{C}$ ), indicating the presence of various mixed oxides that 
were not resolved by XRD. As the $\mathrm{MnO}_{\mathrm{x}}$ layer thickened, the peak at $447^{\circ} \mathrm{C}$ gradually decreased and the peak at $412{ }^{\circ} \mathrm{C}$ became dominant. Deposition of the thinnest $\mathrm{CoMnO}_{\mathrm{x}}$ layer on $\mathrm{Co}_{3} \mathrm{O}_{4}$ led to a reduction peak composed of two components, the first with a peak at $390{ }^{\circ} \mathrm{C}$ corresponding to the reduction of $\mathrm{Co}_{3} \mathrm{O}_{4}$ and the second at $412{ }^{\circ} \mathrm{C}$ attributed to the reduction of $\mathrm{Mn}$ oxide. The thicker deposited $\mathrm{CoMnO}_{\mathrm{x}}$ layer revealed a broadening of the range over which the reduction of each component took place.

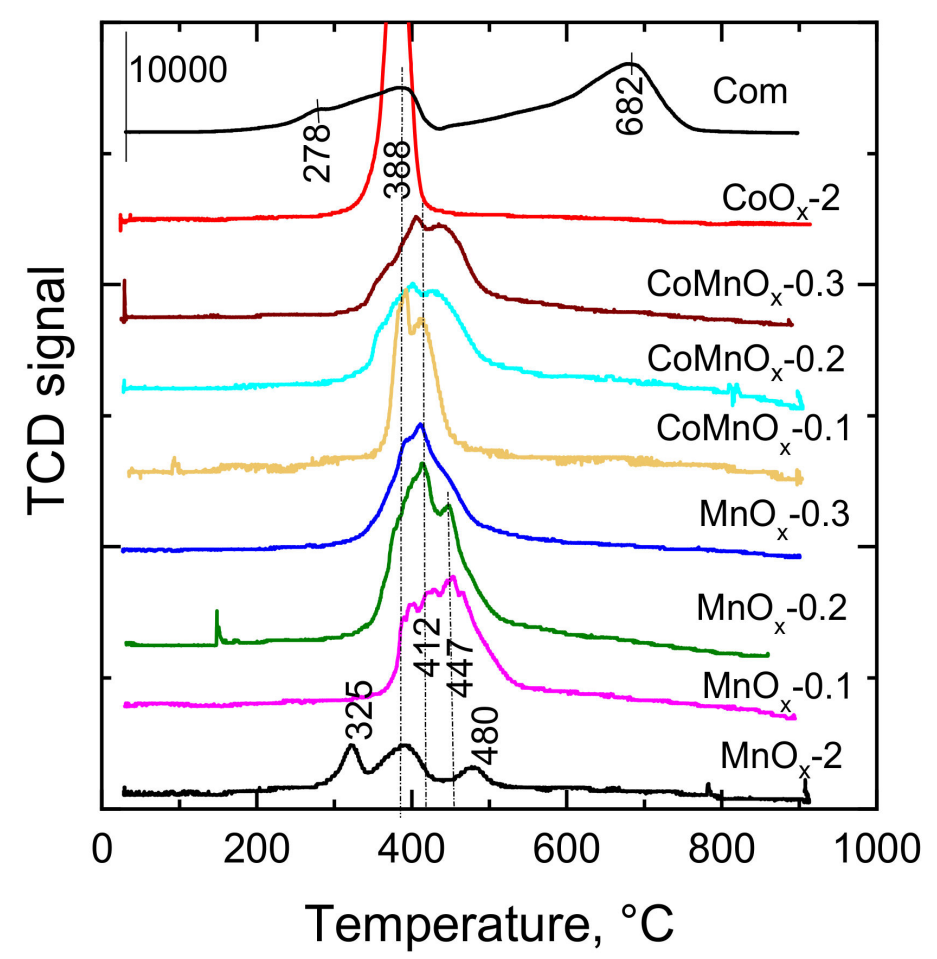

Figure 4. TPR profiles of the examined catalysts.

The reduction of the commercial mixed oxide catalyst Co-Mn-Al (catalyst Com) proceeded in two temperature ranges, the first between 100 and $500{ }^{\circ} \mathrm{C}$, and the second between 500 and $900^{\circ} \mathrm{C}$. Both ranges consist of several overlapping reduction peaks. The first step proves reduction of the $\mathrm{Co}_{3} \mathrm{O}_{4}$ phase and the second reduction of cobalt aluminate arising either during calcination of the catalyst or solid-solid interactions during TPR experiment. $\mathrm{Li}$ et al. [23] observed a similar TPR profile of the Co-Mn-Al mixed oxide obtained at $500{ }^{\circ} \mathrm{C}$ from a coprecipitated precursor.

\subsection{FTIR and Raman Spectroscopy}

Fourier-transform infrared (FTIR) spectra of the prepared catalysts are shown in Figure 5 (left). The spectra were taken in the range from 4000 to $400 \mathrm{~cm}^{-1}$, but analysis was only possible in the range from 900 to $400 \mathrm{~cm}^{-1}$ due to interference from the meshes resulting in artificial bands at wavenumber higher than $900 \mathrm{~cm}^{-1}$. FTIR measurements showed complicated and not easily interpretable spectra. Stretching vibrations of the metal-oxygen bond can be seen between 400 and $900 \mathrm{~cm}^{-1}$. The stretching vibrations at 554 and $659 \mathrm{~cm}^{-1}$ found in the $\mathrm{CoO}_{\mathrm{x}}-2$ catalyst are characteristic of $\mathrm{Co}_{3} \mathrm{O}_{4}$ with a spinel structure [24,25] and the band at $520 \mathrm{~cm}^{-1}$ is typical for the $\mathrm{Mn}-\mathrm{O}$ bond in spinels [26,27].

The low content of active species in the supported catalysts caused low band intensities in their FTIR spectra, yet some interesting features can be documented. Bands at 556, 599, 657 , and $685 \mathrm{~cm}^{-1}$ can be detected in the FTIR spectrum of $\mathrm{CoO}_{\mathrm{x}}-2$ catalyst. These bands confirm the spinel structure of $\mathrm{Co}_{3} \mathrm{O}_{4}$ (with variations between $556-599 \mathrm{~cm}^{-1}$ for the first band and $657-685 \mathrm{~cm}^{-1}$ for the second band) in the catalyst. The first band $v 1$ at $556 \mathrm{~cm}^{-1}$ was attributed to the vibrations of the spinel lattice associated with the Co cations at 
octahedral sites. The second band $v 2$ at ca $657 \mathrm{~cm}^{-1}$ was attributed to the vibrations of the bonds between oxygen and $\mathrm{Co}$ in tetrahedral sites. The FTIR spectrum of the $\mathrm{MnO}_{\mathrm{x}}-2$ catalyst showed a very broad but distinct band with a maximum at 500-510 and a second band at $677 \mathrm{~cm}^{-1}$.
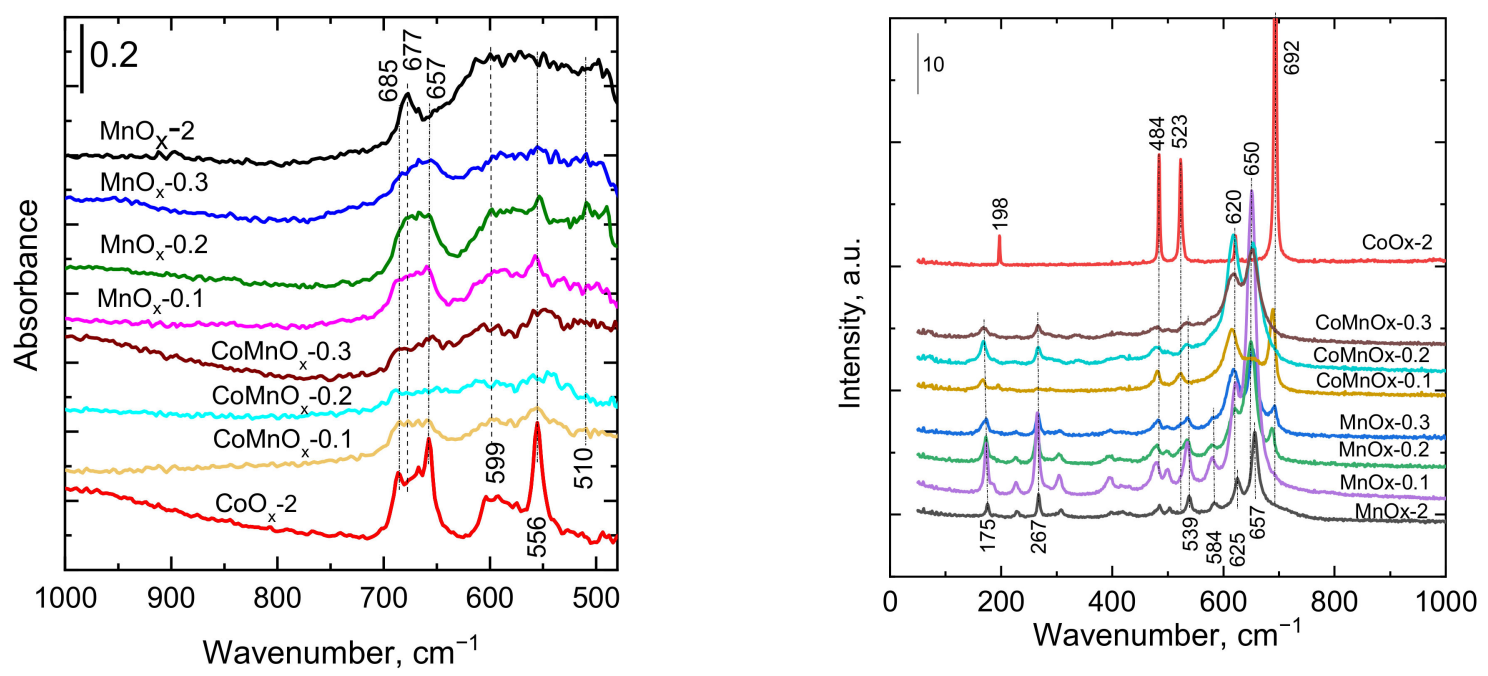

Figure 5. FTIR (left) and Raman (right) spectra of the catalysts.

In the FTIR spectra of cobalt oxide catalysts with additional $\mathrm{CoMnO}_{\mathrm{x}}$ coatings, stretching vibrations of Co-O bonds at 556 and $657 \mathrm{~cm}^{-1}$ can be observed, which were attributed to vibrations of cations in octahedral and tetrahedral sites related to Co-O and/or Mn-O bonds in the spinel structure [28-30]. The FTIR spectra of the $\mathrm{MnO}_{\mathrm{x}}-0.1, \mathrm{MnO}_{\mathrm{x}}-0.2$, and $\mathrm{MnO}_{\mathrm{x}}-0.3$ catalysts show a distinct band in the range $510-500 \mathrm{~cm}^{-1}$, which can be attributed to the $\mathrm{Mn}-\mathrm{O}$ bond in the spinel. The broad band in the range $657-685 \mathrm{~cm}^{-1}$ includes a band attributed to $\mathrm{Mn}-\mathrm{O}$ bonding at $677 \mathrm{~cm}^{-1}$, but a hint of $\mathrm{Co}-\mathrm{O}$ bonding can be observed, probably originating from $\mathrm{Co}_{3} \mathrm{O}_{4}$ previously deposited on the meshes.

The characteristic bands in the Raman spectra (Figure 5 right) may indicate presence of oxide phases that were not detected by powder XRD due to the low content and/or poor structure arrangement of the oxides deposited on the stainless steel meshes. For example, the Raman spectrum of the $\mathrm{MnO}_{\mathrm{x}}-0.3$ catalyst shows peaks corresponding to $\mathrm{Mn}_{\mathrm{x}} \mathrm{O}_{\mathrm{y}}$ crystallographic phase (Figure 5 (right), blue curve). Of course, we cannot rule out the existence of an amorphous phase in the prepared RF thin films. It is true that RF magnetron sputtering shows some inhomogeneity in the thickness of the prepared thin films. This behavior is typical for magnetrons with small diameter (in our case $50 \mathrm{~mm}$ ). On the other hand, a big industrial sputtering magnetron demonstrate excellent homogeneity in the thin film thickness. We believe that this is the reason of dark and light regions observed on the meshes by optical microscopy.

Various authors [31-36] have reported characteristic bands of $\mathrm{Co}$ and $\mathrm{Mn}$ oxides in the Raman spectra. Hadjiev et al. [31] found five Raman active modes of $\mathrm{Co}_{3} \mathrm{O}_{4}$ at 691 (A1g), 618 (F2g), 522 (F2g), 482 (Eg), and 194 (phonon mode F2g) cm ${ }^{-1}$. Tang et al. [32] found analogous $\mathrm{Co}_{3} \mathrm{O}_{4}$ bands at 469, 512, 607 and $674 \mathrm{~cm}^{-1}$. Almost identical bands were observed in the Raman spectrum of the $\mathrm{CoO}_{\mathrm{x}}-2$ catalyst at $695,621,522,484,197 \mathrm{~cm}^{-1}$, proving the presence of $\mathrm{Co}_{3} \mathrm{O}_{4}$. A characteristic $\mathrm{Co}_{3} \mathrm{O}_{4}$ band at $691-695 \mathrm{~cm}^{-1}$ was found in the Raman spectra of all the catalysts investigated except for the $\mathrm{MnO}_{\mathrm{x}}-2$ sample. The presence of $\mathrm{Co}_{3} \mathrm{O}_{4}$ in these catalysts was expected since cobalt oxide obtained by calcination of the precursors from previous magnetron sputtering and electrochemical deposition was the main component of the oxide layer on the stainless steel supports. On the contrary, the absence of the characteristic bands at $510 \mathrm{~cm}^{-1}$ [33] proves the absence of CoO in the catalysts. 
Gao [34] recognized a Raman band of tetragonal rutile-type $\beta-\mathrm{MnO}_{2}$ at $667 \mathrm{~cm}^{-1}$ (A (1g) symmetry) and two bands at 634 and $574 \mathrm{~cm}^{-1}$ belonging to the spectroscopic species $\mathrm{A}(\mathrm{g})$ of the tetragonal hollandite-type framework. Four Raman bands at 655, 366, 310 , and $174 \mathrm{~cm}^{-1}$ were revealed for $\mathrm{Mn}_{2} \mathrm{O}_{3}$ [35]. In the Raman spectrum of $\mathrm{CoMnO}_{3}$, the bands at $665,581,480,369$, and $318 \mathrm{~cm}^{-1}$ were found for $\mathrm{Mn}_{2} \mathrm{O}_{3}$ [36]. Bands associated with Mn oxides can be seen in the Raman spectra of the investigated cobalt oxide catalyst with additional coatings of $\mathrm{MnO}_{\mathrm{x}}$ and $\mathrm{CoMnO}_{\mathrm{x}}$ oxides. The Raman spectra of the supported catalysts indicate the possible presence of $\mathrm{Mn}$ in the form of $\mathrm{Mn}_{2} \mathrm{O}_{3}$, as a strong band at $655 \mathrm{~cm}^{-1}$ was found for all samples except for the $\mathrm{CoMnO}_{\mathrm{x}}-0.1$ catalyst. The bands at 370 and $318 \mathrm{~cm}^{-1}$ characteristic of $\mathrm{Mn}_{3} \mathrm{O}_{4}$ and $\mathrm{CoMnO}_{3}$ were not detected in the Raman spectra of the catalysts. Only in the Raman spectrum of the $\mathrm{MnO}_{\mathrm{x}}-2$ catalyst was there a hint of a band at $667 \mathrm{~cm}^{-1}$ indicating the presence of $\mathrm{MnO}_{2}$. Other Raman bands appearing at 539,581 , and $400-425 \mathrm{~cm}^{-1}$ were not assigned to any standard compound and could be attributed to mixed oxides of $\mathrm{Co}$ and $\mathrm{Mn}$, the presence of which was not indicated by the powder XRD measurements.

The interaction between $\mathrm{Co}_{3} \mathrm{O}_{4}$ platelets and small $\mathrm{MnO}_{x}$ particles produced by additional RF magnetron sputtering could be related to the changes in the intensity of Raman bands associated with Mn oxides observed especially at 174 and $267-269 \mathrm{~cm}^{-1}$. Measurements of Raman spectra also showed inhomogeneity of $\mathrm{MnO}_{\mathrm{x}}$ and $\mathrm{CoMnO}_{\mathrm{x}}$ oxide coatings sputtered on cobalt oxide layers deposited on stainless steel meshes. When focusing the laser beam, light and dark regions were observed on the surface of the catalysts by optical microscopy. Different Raman spectra were taken from the light and dark regions indicating the presence of $\mathrm{Co}$ and $\mathrm{Mn}$ rich oxides (Figure 6). The expected interaction between small $\mathrm{MnO}_{\mathrm{x}}$ and $\mathrm{CoMnO}_{\mathrm{x}}$ particles with $\mathrm{Co}_{3} \mathrm{O}_{4}$ platelets during additional plasma sputtering is likely to lead to the formation of additional Co-Mn mixed oxides compared to the production of Co-Mn mixed oxides from coprecipitated precursors.
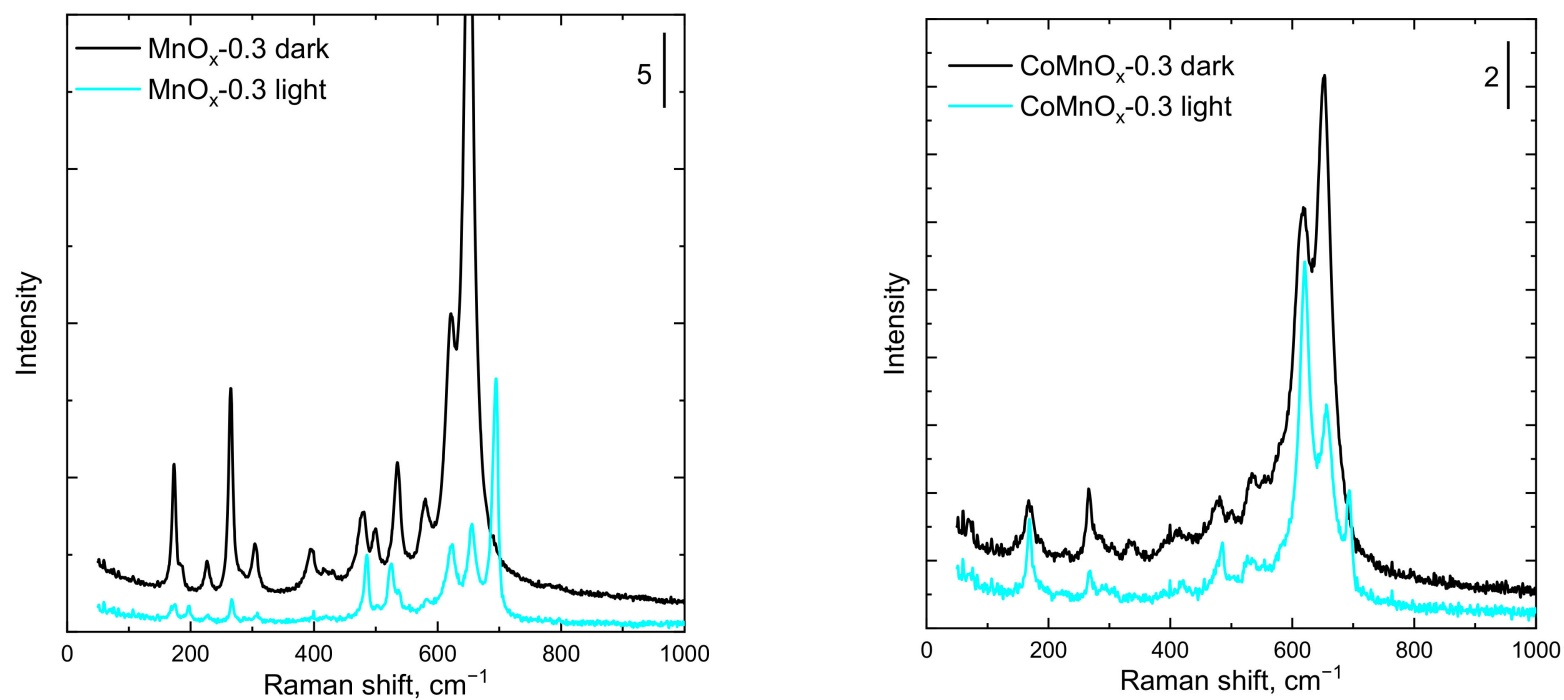

Figure 6. Raman spectra of $\mathrm{MnOx}-0.3$ (left) and $\mathrm{CoMnOx}-0.3$ (right) catalysts determined in two different points, light and dark.

\subsection{XPS}

The surface composition of the catalysts in the near-surface region and the chemical state of the elements were determined using XPS. Full compensation of the sample charge by correcting for carbon shift was not possible because the samples used in the XPS measurements were in the form of stainless steel meshes coated with Co-Mn oxide. It was therefore not possible to distinguish between carbon originating from the underlying carbon tape and from adventitious carbon compounds on the catalyst surface. Thus, it was necessary to calibrate the spectra according to oxygen (corresponding to a metal-oxygen bonding energy in the metal oxide of $529.6 \mathrm{eV}$ ). The surface concentrations determined 
by XPS are shown in Table 4 without carbon and oxygen because of the high amount of carbon from the tape and because of the large proportion of oxygen bound to adventitious carbon impurities.

In addition to the main components ( $\mathrm{Co}, \mathrm{Mn}, \mathrm{O}), \mathrm{Fe}$ originating from the support was found in some catalysts. Potassium was also detected on the surface of three catalysts $\left(\mathrm{MnO}_{\mathrm{x}}-0.2, \mathrm{CoMnO}_{\mathrm{x}}-0.1\right.$, and $\left.\mathrm{CoMnO}_{\mathrm{x}}-0.2\right)$. A small amount of potassium probably remained in washed samples after electrochemical deposition, in which potassium nitrate was used as the supporting electrolyte. In the Co-Mn-Al mixed oxide (Com catalyst), $\mathrm{Al}$, $\mathrm{K}$ and $\mathrm{Na}$ were detected as major and minor components, respectively, along with $\mathrm{Co}$, $\mathrm{Mn}$, and $\mathrm{O}$.

Table 4. Surface composition of the catalysts (at. \%) determined by X-ray photoelectron spectrometry (without carbon and oxygen components).

\begin{tabular}{cccccccc}
\hline Catalyst & Co 2p & Mn 2p & Fe2p & K 2p & Al 2p & Na 1s & Co/(Co + Mn) XPS \\
\hline $\mathrm{MnO}_{\mathbf{x}}-2$ & 0.0 & 91.9 & 8.1 & 0.0 & 0.0 & 0.0 & 0.00 \\
$\mathrm{MnO}_{\mathbf{x}}-0.1$ & 30.7 & 63.8 & 5.5 & 0.0 & 0.0 & 0.0 & 0.33 \\
$\mathrm{MnO}_{\mathbf{x}}-0.2$ & 20.0 & 62.8 & 10.8 & 6.4 & 0.0 & 0.0 & 0.24 \\
$\mathrm{MnO}_{\mathrm{x}}-0.3$ & 17.9 & 73.8 & 8.3 & 0.0 & 0.0 & 0.0 & 0.20 \\
$\mathrm{CoMnO}_{\mathrm{x}}-0.1$ & 24.5 & 50.6 & 5.3 & 19.6 & 0.0 & 0.0 & 0.33 \\
$\mathrm{CoMnO}_{\mathrm{x}}-0.2$ & 23.9 & 62.3 & 5.6 & 8.2 & 0.0 & 0.0 & 0.28 \\
$\mathrm{CMnO}_{\mathrm{x}}-0.3$ & 14.7 & 80.2 & 5.1 & 0.0 & 0.0 & 0.0 & 0.16 \\
$\mathrm{CoO}_{\mathbf{x}}-2$ & 100.0 & 0.0 & 0.0 & 0.0 & 0.0 & 0.0 & 1.00 \\
$\mathrm{Com}^{\mathrm{a}}$ & 48.0 & 11.6 & 0.0 & 8.0 & 32.5 & 2.8 & 0.81 \\
\hline
\end{tabular}

a Pelletized commercial Co-Mn-Al mixed oxide catalyst.

Deconvolution of the spectra of $\mathrm{Co}, \mathrm{Mn}$ and $\mathrm{O}$ (Table 5) showed their oxidation states. Comparison of the two major photoemission maxima of Co $2 \mathrm{p}_{1 / 2}$ and Co $2 \mathrm{p}_{3 / 2}$ showing spin-orbit splitting of $15.2 \pm 0.1 \mathrm{eV}$ with the reported value $(15.1 \mathrm{eV})$ along with the observed broad satellite structure [37] suggests the presence of cobalt in divalent and trivalent oxidation states [38]. The Co $2 \mathrm{p}$ spectra consist of two contributions, $\mathrm{CoO}$ and $\mathrm{Co}_{3} \mathrm{O}_{4}$. Fitting these peaks is challenging because their maxima are fixed at the same position and their peaks differ only in FWHM value and shape. Therefore, the reports are not consistent in their assignment to the individual oxidation states. Based on the recent XPS studies using appropriate standards [39-41], we assigned the cobalt component with lower binding energy $(780 \mathrm{eV})$ to tetrahedral $\mathrm{Co}^{2+}$ and that with higher binding energy (781.3 and $788 \mathrm{eV}$ ) to octahedral $\mathrm{Co}^{3+}$. However, opposite assignment can also be found in the literature [42].

Table 5. Normalized concentrations of deconvoluted $\mathrm{Co} 2 \mathrm{p}, \mathrm{Mn} 2 \mathrm{p}$ and $\mathrm{O} 1 \mathrm{~s}$ peaks (in rel. \%) and molar ratios of $\mathrm{Co}^{3+} / \mathrm{Co}^{2+}$, $\mathrm{Mn}^{3+} / \mathrm{Mn}^{4+}$, and oxygen vacancies $\mathrm{O}_{\mathrm{v}} /(\mathrm{Co}+\mathrm{Mn})$ ions.

\begin{tabular}{|c|c|c|c|c|c|c|c|c|c|c|c|c|}
\hline eV & $\mathrm{Co}^{2+}$ & $\begin{array}{c}\mathrm{Co}^{3+} \\
780.5- \\
780.8\end{array}$ & $\begin{array}{c}\mathrm{Co}^{3+} \\
783.0- \\
783.5\end{array}$ & $\begin{array}{l}\mathrm{Mn}^{3+} \\
641.3- \\
641.9\end{array}$ & $\begin{array}{c}\mathrm{Mn}^{4+} \\
643.2- \\
643.9\end{array}$ & $\mathrm{Mn}^{2+}$ & 529.6 & 531.0 & $\mathrm{O}_{\mathrm{w}}$ & $\mathrm{Co}^{2+} / \mathrm{Co}^{3+}$ & $\begin{array}{c}\mathrm{Mn}^{3+} / \mathrm{Mn}^{4+} \\
\text { Peak (1/2) }\end{array}$ & $\begin{array}{c}\mathrm{O}_{\mathrm{v}} \\
/(\mathrm{Co}+\mathrm{Mn}) \\
-\end{array}$ \\
\hline $\mathrm{MnO}_{\mathrm{x}}-2$ & 0 & 0 & 0 & 71.7 & 21.3 & 6.9 & 54.9 & 16.0 & 29.2 & - & 3.4 & 0.5 \\
\hline $\mathrm{MnO}_{\mathrm{x}}-0.1$ & 52.3 & 39.9 & 7.8 & 72.2 & 27.8 & 0.0 & 25.8 & 9.3 & 64.9 & 1.1 & 2.6 & 0.6 \\
\hline $\mathrm{MnO}_{\mathrm{x}}-0.2$ & 52.9 & 43.9 & 3.2 & 67.9 & 32.1 & 0.0 & 23.0 & 9.4 & 67.6 & 1.1 & 2.1 & 0.7 \\
\hline $\mathrm{MnO}_{\mathrm{x}}-0.3$ & 50.5 & 36.7 & 12.8 & 74.3 & 25.7 & 0.0 & 21.3 & 10.7 & 68.0 & 1.0 & 2.9 & 0.9 \\
\hline $\mathrm{CoMnO}_{\mathrm{x}}-0.1$ & 47.5 & 40.0 & 12.5 & 76.3 & 23.7 & 0.0 & 53.9 & 21.6 & 24.5 & 0.9 & 3.2 & 0.8 \\
\hline $\mathrm{CoMnO}_{\mathrm{x}}-0.2$ & 46.7 & 38.4 & 14.9 & 72.4 & 27.6 & 0.0 & 35.4 & 16.2 & 48.4 & 0.9 & 2.6 & 0.8 \\
\hline $\mathrm{CoMnO}_{\mathrm{x}}-0.3$ & 53.0 & 34.4 & 12.6 & 69.3 & 30.7 & 0.0 & 45.1 & 24.0 & 30.9 & 1.1 & 2.3 & 0.8 \\
\hline $\mathrm{CoO}_{x}-2$ & 50.6 & 47.1 & 2.2 & 0.0 & 0.0 & 0.0 & 35.9 & 34.0 & 30.1 & 1.0 & - & 1.5 \\
\hline $\operatorname{Com}^{\mathrm{a}}$ & 57.9 & 31.6 & 10.5 & 72.5 & 27.5 & 0.0 & 63.3 & 36.2 & 0.5 & 1.4 & 2.6 & 1.2 \\
\hline
\end{tabular}

a Pelletized commercial Co-Mn-Al mixed oxide catalyst. 
Manganese $\mathrm{Mn} 2 \mathrm{p}_{3 / 2}$ spectra showed one broad peak with a maximum at $641.0-641.9 \mathrm{eV}$, indicating the presence of more than one oxidation state of Mn [43]. Determination of the manganese oxidation states was done as reported previously $[39,44]$. The Mn $2 \mathrm{p}_{3 / 2}$ spectrum was fitted by two peaks: $\mathrm{Mn}^{3+}$ (a component with binding energy of $639.4 \mathrm{eV}$ ) and $\mathrm{Mn}^{4+}$ (a component with binding energy of $641.0 \mathrm{eV}$ ). The data are summarized in Table 5. As expected, the surface cobalt concentration decreased with increasing thickness of the deposited Mn or Co + Mn oxide layers, while the surface manganese concentration increased with thickness. The $\mathrm{Co} /(\mathrm{Co}+\mathrm{Mn})_{\mathrm{XPS}}$ ratio was also decreasing with the thickness of layers (Table 4).

The deconvolution of $\mathrm{O} 1 \mathrm{~s}$ spectra revealed three peaks with binding energies of about $529.6,531.3 \mathrm{eV}$, and $532.9 \mathrm{eV}$. The first peak at $529.6 \mathrm{eV}$ was attributed to lattice oxygen $\left(\mathrm{O}_{1}\right)$ in the metal oxides. The second peak centred at $531.3 \mathrm{eV}$ corresponded to regions containing oxygen vacancies (oxygen-deficient regions) $\mathrm{O}_{\mathrm{v}}$ [45], whereas the third peak around $532.9 \mathrm{eV}$ was attributed to a mixture of hydroxyl species of water $\mathrm{O}_{\mathrm{w}}$ adsorbed on the surface and oxygen bound to carbon from adventitious carbon admixtures [46,47]. The proportion of oxygen vacancies belonging to Co and Mn oxides (Table 5) was calculated as the ratio of the oxygen $\mathrm{O}_{\mathrm{v}}$ concentration to the sum of $\mathrm{Co}(2 \mathrm{p})$ and $\mathrm{Mn}(2 \mathrm{p})$ concentrations (in at. \%). By analysing XPS data, it appears that the uncertainty in deconvolution of oxygen is much larger than in our previous work [10]. The main difference is in the $\mathrm{O}_{\mathrm{v}} / \mathrm{O}_{\mathrm{w}}$ ratio. In our previous article, the amount of $\mathrm{O}_{\mathrm{w}}$ was significantly lower than that of $\mathrm{O}_{\mathrm{v}}$ and therefore it was possible to determine the value of $\mathrm{O}_{\mathrm{v}}$ with a reasonable precision. On the other hand, with our current data, the $\mathrm{O}_{w}$ values exceed $\mathrm{O}_{v}$ values for most of the catalysts. In some cases, the $\mathrm{O}_{\mathrm{w}}$ is more than five times higher than $\mathrm{O}_{\mathrm{v}}$. This results in a high uncertainty in the deconvolution of $\mathrm{O}_{v}$, which could lead to a significant distortion of the $\mathrm{O}_{\mathrm{v}} /(\mathrm{Co}+\mathrm{Mn})$ value in comparison with our previous article.

The increased value of $\mathrm{O}_{\mathrm{w}}$ is connected with significantly higher carbon content on the surface of the catalysts originating from adventitious impurities. As the final RF process was done under vacuum, there should not be excess of carbon from the preparation procedure. Therefore, we assume that the surface of the catalysts is able to capture more adventitious impurities than the samples from our previous article (there was not any change in sample handling). The main difference between these series of samples is a surface morphology. As the current samples are much more forked, it can lead to better capture of adventitious impurities into cavities. The morphology of the surface can also affect catalytic activity, as there might be higher number of edge sites connected with catalytic efficiency. Values of deconvoluted XPS spectra of the individual elements in the catalysts are shown in Table 5. The XPS measurements showed that the ratio of $\mathrm{Co}^{2+}$ and $\mathrm{Co}^{3+}$ ions did not vary much from one catalyst to another (Table 4). Approximately equal amount of $\mathrm{Co}^{2+}$ and $\mathrm{Co}^{3+}$ occurred on the surface of all structured catalysts. The XPS measurements confirmed that surface Mn oxides occurred mainly as $\mathrm{Mn}^{3+}$ on the surface of all sputtered catalysts, which predominated over $\mathrm{Mn}^{4+}$ by a factor of 2-3 regardless of the way of the source of magnetron sputtering. These results are in agreement with the results of Raman spectra. The findings suggest that there is no significant diffusion of Co cations into the $\mathrm{MnO}_{\mathrm{x}}$ coatings.

\subsection{Activity in Ethanol Oxidation}

The prepared catalysts were tested in the total oxidation of ethanol. The ethanol conversions over oxide catalysts deposited on stainless steel meshes and Com catalyst in the form of pellets and grains are shown in Figure 7. Characteristic values describing the catalytic activity and selectivity in ethanol oxidation are summarized in Table 6 . The $T_{50}$ temperatures, at which $50 \%$ ethanol conversion was achieved, ranged from $221^{\circ} \mathrm{C}$ for the $\mathrm{MnO}_{\mathrm{x}}-2$ catalyst to $242{ }^{\circ} \mathrm{C}$ for the $\mathrm{CoO}_{x}-2$ catalyst. Based on the $T_{50}$ values, ethanol oxidation proceeded slightly more efficiently over the $\mathrm{Co}_{3} \mathrm{O}_{4}$ catalysts coated with $\mathrm{MnO}_{\mathrm{x}}$. The difference in $T_{50}$ between the groups of catalysts coated with $\mathrm{MnO}_{\mathrm{x}}$ and $\mathrm{CoMnO}_{\mathrm{x}}$ was 
about $15{ }^{\circ} \mathrm{C}$. Performance of the catalysts slightly increased with increasing amount of the sputtered $\mathrm{MnO}_{\mathrm{x}}$ and $\mathrm{CoMnO}_{\mathrm{x}}$ oxides.

In the presence of pelletized commercial Co-Mn-Al mixed oxide (the Com catalyst), ethanol oxidation proceeded gradually with increasing reaction temperature, while a steep increase was observed over the oxide catalyst deposited on stainless steel meshes. Deceleration of ethanol oxidation in the presence of pelletized Com catalyst was connected with the internal diffusion of the reactant and reaction products from the interior of the pellets to their surface. The course of ethanol oxidation over the small grains of Com catalyst confirmed the influence of internal diffusion in the pelletized Com catalyst. Small grains of the Com catalyst oxidized ethanol at low reaction temperatures with $T_{50}$ of $107^{\circ} \mathrm{C}$, while the pelletized catalyst oxidized ethanol at substantially higher temperature $\left(T_{50}\right.$ of $187^{\circ} \mathrm{C}$ ). The $\mathrm{T}_{90} \mathrm{CO}_{2}$ temperature necessary for achieving the complete oxidation of all organic compounds to $\mathrm{CO}_{2}$ is, however, more important than the $T_{50}$ temperature. Absence of internal diffusion in the small grains of Com catalyst resulted in achieving the total oxidation of ethanol at about $280^{\circ} \mathrm{C}$, while in the presence of pellets the $\mathrm{T}_{90} \mathrm{CO}_{2}$ temperature was higher than $400^{\circ} \mathrm{C}$.

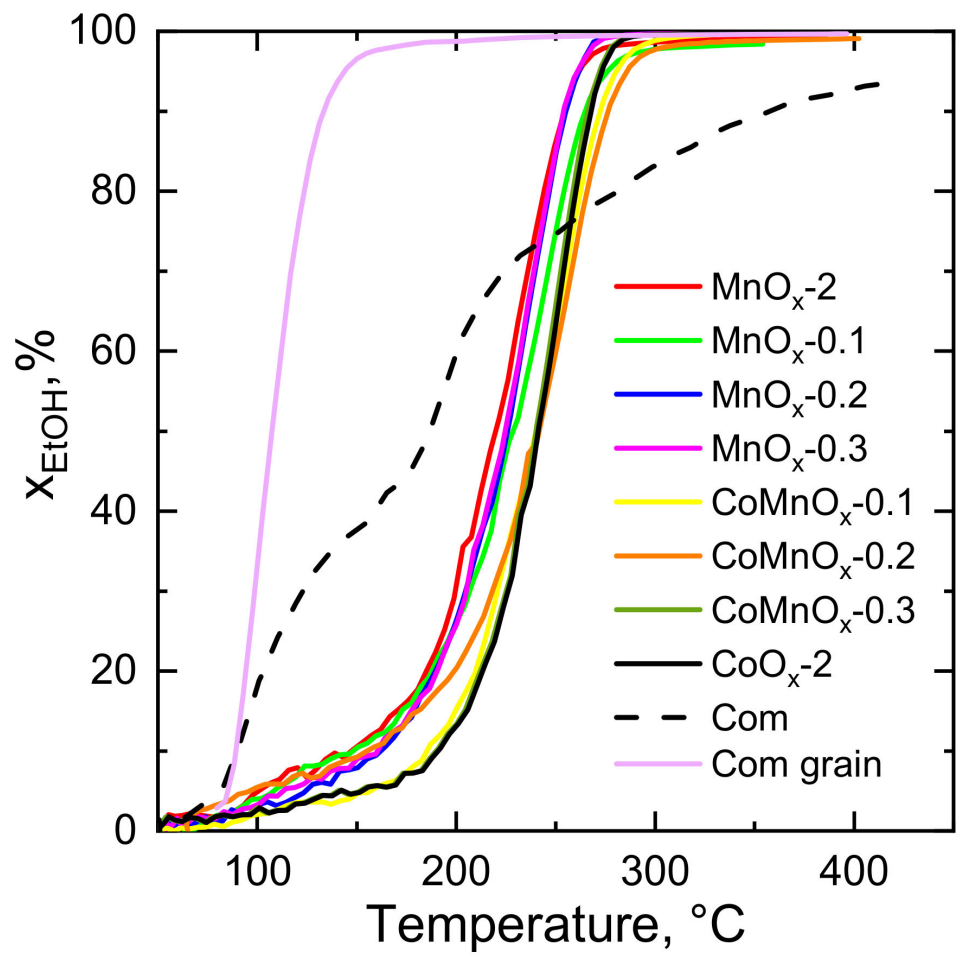

Figure 7. Dependence of ethanol conversion on the reaction temperature for the investigated catalysts in the form of meshes and of Com catalyst in the form of pellets and grains.

The thin layer of active oxide components in the structured catalysts, causing practically negligible effect of internal diffusion, resulted in a steep increase in ethanol conversion with increasing reaction temperature. The new investigated structured catalysts in the form of meshes showed similar temperatures for achieving the complete oxidation of ethanol as the grains of commercial catalyst.

The Com catalyst showed higher conversion of ethanol at low reaction temperatures in comparison with the examined structured catalysts deposited on stainless steel meshes (Figure 7). It should be noted that the Com catalyst, tested in the form of $5 \times 5 \mathrm{~mm}$ pellets, had a high bulk density and a relatively high surface area, approximately five times higher compared to the oxides deposited on stainless steel meshes (115 vs. about $20 \mathrm{~m}^{2} \mathrm{~g}_{\text {oxide }}{ }^{-1}$, respectively, Table 2). In the catalytic experiments, larger amount of the Com catalyst, approximately 3.7 times more than the structured catalysts was necessary 
to achieve the same selected catalyst space velocity $\left(20 \mathrm{l} \mathrm{h} \mathrm{gcat}^{-1}\right)$, indicating a greater ability of the Com catalyst to adsorb the reactant at low reaction temperatures resulting in seemingly enhanced ethanol conversion. However, the complete conversion of all organic compounds in the reaction mixture is critical for the removal of pollutants from the air; therefore, the temperature, at which these high conversions are achieved, represents an important parameter.

Table 6. Performance of the catalysts in ethanol oxidation (eight meshes, GHSV $=21 \pm 1 \mathrm{~L} \mathrm{gcat}^{-1} \mathrm{~h}^{-1}$, $760 \mathrm{ppm}$ of ethanol, temperature ramp $2{ }^{\circ} \mathrm{C} \mathrm{min}^{-1}$ ).

\begin{tabular}{|c|c|c|c|c|c|c|c|}
\hline Catalyst & $\begin{array}{c}\mathrm{T}_{50} \mathrm{EtOH} \\
{ }^{\circ} \mathrm{C}\end{array}$ & $\begin{array}{c}\mathbf{A c A}_{\max } \\
{ }^{\circ} \mathrm{C}\end{array}$ & $\begin{array}{c}\mathbf{A c A}_{\max } \\
\text { ppm }\end{array}$ & $\begin{array}{c}\mathrm{CO}_{\max } \\
{ }^{\circ} \mathrm{C}\end{array}$ & $\begin{array}{c}\mathrm{CO}_{\max } \\
\mathrm{ppm}\end{array}$ & $\begin{array}{c}\mathrm{T}_{90} \mathrm{CO}_{2} \\
{ }^{\circ} \mathrm{C}\end{array}$ & $\begin{array}{c}R_{200} \\
\text { mmol }_{\text {EtOH }} \\
\text { goxides }^{-1} \mathrm{~h}^{-1}\end{array}$ \\
\hline $\mathrm{MnO}_{\mathrm{x}}-2$ & 221 & 249 & 491 & 324 & 210 & 282 & 46.9 \\
\hline $\mathrm{MnO}_{\mathrm{x}}-0.1$ & 228 & 263 & 456 & 286 & 135 & 296 & 33.1 \\
\hline $\mathrm{MnO}_{\mathrm{x}}-0.2$ & 225 & 254 & 505 & 279 & 119 & 285 & 28.4 \\
\hline $\mathrm{MnO}_{\mathrm{x}}-0.3$ & 224 & 250 & 523 & 280 & 113 & 284 & 28.4 \\
\hline $\mathrm{CoMnO}_{\mathrm{x}}-0.1$ & 240 & 260 & 436 & 284 & 89 & 307 & 24.1 \\
\hline $\mathrm{CoMnO}_{\mathrm{x}}-0.2$ & 240 & 268 & 443 & 292 & 107 & 301 & 20.8 \\
\hline $\mathrm{CoMnO}_{\mathrm{x}}-0.3$ & 235 & 259 & 332 & 284 & 89 & 293 & 20.9 \\
\hline $\mathrm{CoO}_{\mathrm{x}}-2$ & 242 & 294 & 521 & 289 & 60 & 294 & 12.4 \\
\hline $\operatorname{Com}^{\mathrm{a}}$ & 187 & 169 & 158 & 195 & 15 & 405 & 0.54 \\
\hline
\end{tabular}

The specific catalytic activity $R_{200}$, expressed as mmol of ethanol converted per gram of $\mathrm{Co}$ and $\mathrm{Mn}$ oxides and hour at $200{ }^{\circ} \mathrm{C}$, was chosen to compare more accurately the performance of the catalysts containing various amounts of active oxide components. According to the $R_{200}$ values, the highest catalytic activity was found for the $\mathrm{MnO}_{\mathrm{x}}-2$ catalyst. Compared to order of the $T_{50}$ temperatures, the order of catalytic activity was slightly different; the $\mathrm{MnO}_{\mathrm{x}}-0.1$ catalyst was the most active among all the catalysts investigated (Table 6). This was very likely due to a possible interaction between the $\mathrm{MnO}_{\mathbf{x}}$ particles and the $\mathrm{Co}_{3} \mathrm{O}_{4}$ platelets. Despite more than 360-570 times lower content of the Co and $\mathrm{Mn}$ oxides in the catalytic bed compared to the pelletized commercial Co-Mn-Al catalyst, the structured catalysts exhibited higher (23-87 times) catalytic performance in ethanol oxidation (Table 6).

The selectivity of the catalysts to carbon dioxide varied slightly with the catalyst composition. Acetaldehyde (AcA) was found to be the major by-product of ethanol oxidation over all the structured catalysts. The typical evolution of reaction by-products during ethanol oxidation is shown in Figure 8.

The maximum concentration of acetaldehyde was formed at the temperatures between 249 and $268{ }^{\circ} \mathrm{C}$ for the $\mathrm{MnO}_{\mathrm{x}}-2$ and $\mathrm{CoMnO}_{\mathrm{x}}-0.2$ catalysts. The values of the maximum acetaldehyde concentration ranged from 332 to $523 \mathrm{ppm}$ for the $\mathrm{CoMnO}_{\mathrm{x}}-0.3$ and $\mathrm{MnO}_{\mathbf{x}}$ 0.3 catalysts containing the thickest oxide coatings prepared by additional magnetron sputtering (Table 6). The evolution of acetaldehyde over the pelletized Co-Mn-Al mixed oxide catalyst (the Com catalyst) was much lower (158 ppm) and occurred at a relatively low temperature $\left(169^{\circ} \mathrm{C}\right)$.

The concentration of carbon monoxide as the other important by-product in the reaction mixture also varied with the catalysts' composition. The maximum concentration of $\mathrm{CO}$ formed (210 ppm) was found over the most active catalyst, $\mathrm{MnO}_{\mathrm{x}}-2$, while the lowest CO concentration was found over the Com catalyst (15 ppm).

The formation of dangerous intermediate products of ethanol oxidation, acetaldehyde and $\mathrm{CO}$, is a serious problem, which is overcome in the industrial units by the injection of the reaction mixture to a catalyst bed whose temperature ensures sufficient ethanol and reaction byproducts conversion. We have demonstrated that such temperature, illustrated as the temperature needed to achieve $90 \%$ conversion of ethanol to carbon dioxide, $T_{90}\left(\mathrm{CO}_{2}\right)$, was much lower for our structured catalysts (from 282 to $307^{\circ} \mathrm{C}$ ) compared to the pelleted industrial Com catalyst $\left(405^{\circ} \mathrm{C}\right)$. 


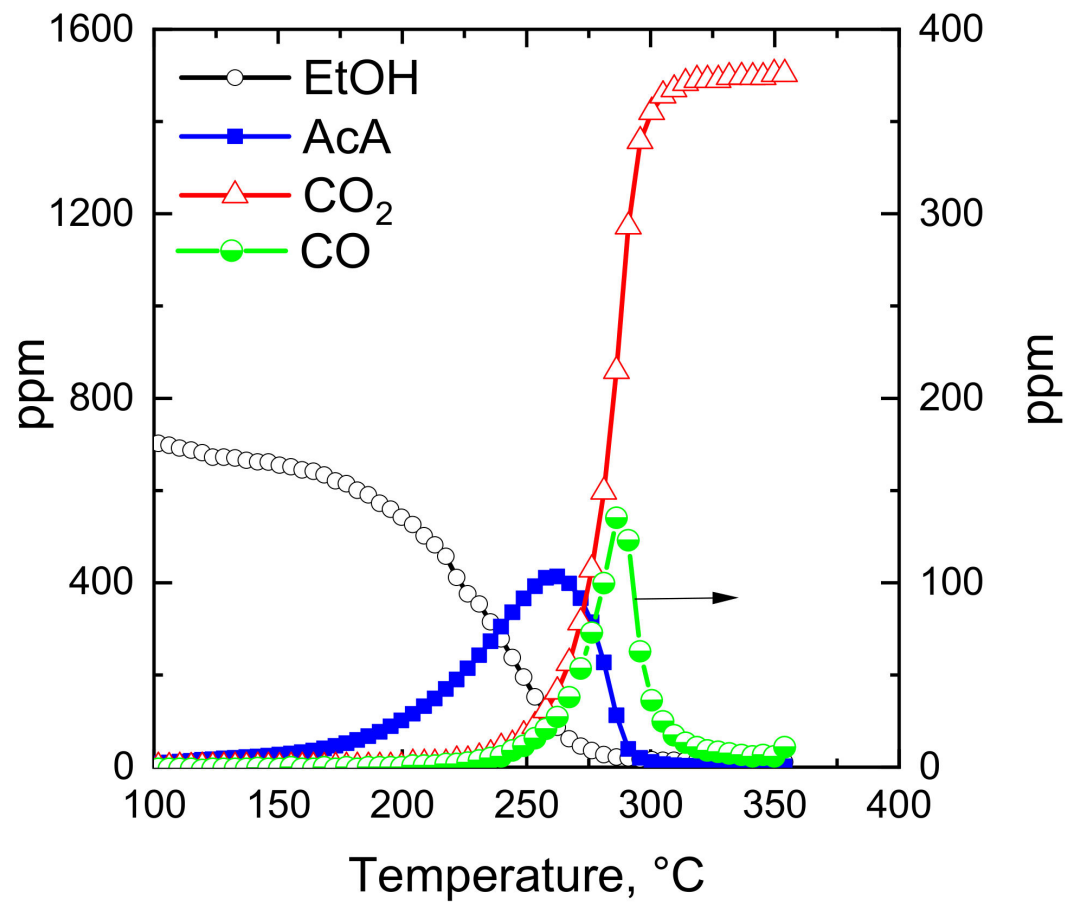

Figure 8. Formation of by-products during ethanol oxidation over the $\mathrm{MnOx}-0.1$ catalyst in dependence on the reaction temperature (temperature ramp $2{ }^{\circ} \mathrm{C} \min ^{-1}$ ).

The stability of catalyst activity is an important parameter. The standard procedure for testing catalysts involved four consecutive light-off experiments. Comparison of the first and fourth test showed that the activity of the catalysts was stable (i.e., the difference was in the frame of the experimental error). For example, for the $\mathrm{MnO}_{\mathrm{x}}-0.3$ catalyst the initial ethanol conversion at $200{ }^{\circ} \mathrm{C}$ was $25.8 \%$ while that after the fourth cycle reached $24.6 \%$. With respect to the relatively short time of catalyst examination (four consecutive cycles of light-off experiments), we do not suppose extensive changes in physical chemical properties of the catalysts. To illustrate this statement, the XPS experiment with the fresh and spent $\mathrm{MnO}_{\mathrm{x}}-0.1$ catalyst was performed. It showed no significant changes in elemental composition of the surface. The $\mathrm{Co} /(\mathrm{Co}+\mathrm{Mn})$ ratio was 0.33 and 0.34 for the fresh and spent catalyst, respectively. Deconvolution of the Co $2 p$ and Mn 2p spectra showed only small changes in the oxidation states. The $\mathrm{Co}^{2+} / \mathrm{Co}^{3+}$ ratio changed from 1.1 to 1.0 , while the $\mathrm{Mn}^{3+/ \mathrm{Mn} 4+}$ ratio was 2.6 and 2.4, respectively. Thus, it is seen that the possible changes in catalyst properties introduced by catalytic experiments are less important compared to the differences among the catalysts due to different preparation procedures.

\section{Discussion}

We have recently shown that mixed Co-Mn oxide catalysts deposited on stainless steel meshes by hydrothermal synthesis exhibited higher catalytic activity than single Co and Mn oxides [7-9]. We have also demonstrated that electrochemically deposited cobalt oxide is highly catalytically active but suffers from poor mechanical stability. The intention of this work was to (i) enhance the catalytic activity of the cobalt oxide catalysts prepared by $\mathrm{Mn}$ oxide incorporation and (ii) improve the mechanical stability of electrochemically deposited cobalt oxide. Both objectives will be achieved by (i) pretreating the stainless steel meshes by magnetron sputtering of Co to improve the adhesion of the subsequently electrochemically deposited cobalt oxide and (ii) coating the electrochemically deposited cobalt oxide with a layer of $\mathrm{Co}$ and Mn oxides by magnetron sputtering. Thus, the chosen catalyst preparation procedure, i.e., coating of the stainless steel meshes with a thin film of cobalt oxide by RF magnetron sputtering, electrochemical deposition of the cobalt hydroxide precursor 
followed by calcination to obtain a $\mathrm{Co}_{3} \mathrm{O}_{4}$ layer, and finally, additional coating of the deposited cobalt oxide with $\mathrm{MnO}_{\mathrm{x}}$ or $\mathrm{CoMnO}_{\mathrm{x}}$ oxides by $\mathrm{RF}$ magnetron sputtering should thus enhance the catalytic activity. In addition, sufficient adhesion of the active layer to the stainless steel mesh would also be expected.

Catalytic activity $R_{200}$ evaluated for the as-prepared catalysts ranged from 12 to $47 \mathrm{mmol}$ $\mathrm{EtOH} \mathrm{g}{ }^{-1} \mathrm{~h}^{-1}$ and was comparable to that found for structured Co-Mn mixed oxide catalysts prepared from hydrothermally crystallized carbonate precursors (from 7 to $21 \mathrm{mmol}$ $\mathrm{EtOH} \mathrm{g}{ }^{-1} \mathrm{~h}^{-1}$ ) [6]. However, the content of active $\mathrm{Co}$ and Mn oxide components in the latter catalysts was approximately 2 to 10 times higher. This indicates that the method used for the catalysts preparation in this study allowed to reduce the amount of active components in the catalysts without a significant decrease in catalytic activity. Although the single component $\mathrm{MnO}_{\mathrm{x}}-2$ catalyst exhibited the highest catalytic activity (lowest $T_{50}$ temperature and highest $R_{200}$ value), the concentration of $\mathrm{CO}$ formed on this catalyst was almost twice the concentration observed on the supported cobalt oxide with additional $\mathrm{MnO}_{\mathrm{x}}$ and $\mathrm{CoMnO}_{\mathrm{x}}$ coatings. Thus, $\mathrm{MnO}_{\mathrm{x}}$ catalyzes the oxidation of ethanol with a higher reaction rate, but the rate of subsequent oxidation of $\mathrm{CO}$ to $\mathrm{CO}_{2}$ is much lower than that observed in the presence of cobalt oxide additionally coated with Mn oxide.

In order to demonstrate the efficiency of the studied catalysts, their activity in ethanol oxidation was compared with that of the EnviCat ${ }^{\circledR}$ VOC-1544 catalyst [48]. This commercial $\mathrm{Cu}-\mathrm{Mn} / \mathrm{Al}_{2} \mathrm{O}_{3}$ catalyst contained $5.4 \mathrm{wt} . \% \mathrm{Mn}$ and $3.3 \mathrm{wt} . \% \mathrm{Cu}$. In ethanol oxidation (100 ppm at the GHSV of $71 \mathrm{~L} \mathrm{~g}_{\mathrm{cat}}{ }^{-1} \mathrm{~h}^{-1}$ ), the $T_{50}$ temperature was reached at $142{ }^{\circ} \mathrm{C}$. This result may seem to be better that those obtained with our catalysts (the $T_{50}$ was ranging from from $221{ }^{\circ} \mathrm{C}$ for the $\mathrm{MnO}_{\mathrm{x}}-2$ catalyst to $242{ }^{\circ} \mathrm{C}$ for the $\mathrm{CoO}_{\mathrm{x}}-2$ catalyst). However, the amount of the active phase (metal oxides) in the catalyst bed was for the EnviCat ${ }^{\circledR}$ VOC-1544 catalyst much higher (1.39 $\mathrm{g}$ compared to $0.02-0.03 \mathrm{~g}$ for our catalysts). The conversion of ethanol achieved with the EnviCat ${ }^{\circledR}$ VOC- 1544 catalyst at $200{ }^{\circ} \mathrm{C}$ was $87.5 \%$, and thus the catalytic activity $R_{200}$ was $3.5 \mathrm{mmol} \mathrm{goxides}^{-1} \mathrm{~h}^{-1}$. This is much lower catalytic activity compared to that of our Co-Mn catalysts, ranging from 12.4 to 46.9 mmol goxides $^{-1} \mathrm{~h}^{-1}$ (Table 6).

The surface composition of the cobalt oxide catalysts additionally coated with $\mathrm{MnO}_{\mathrm{x}}$ and $\mathrm{CoMnO}_{\mathrm{x}}$ oxides also showed some differences compared to the composition found for the structured Co-Mn mixed oxide catalysts obtained from carbonate precursors crystallized under hydrothermal conditions on the stainless steel supports. The catalytic activity of the $\mathrm{MnO}_{x}-2$ catalyst was found to be almost four times higher than that of the $\mathrm{CoO}_{x}-2$ catalyst. The $R_{200}$ activity of the structured cobalt oxides modified with additional coatings of $\mathrm{MnO}_{\mathrm{x}}$ or $\mathrm{CoMnO}_{\mathrm{x}}$ oxides underwent a maximum around the $\mathrm{Co} /(\mathrm{Co}+\mathrm{Mn})_{\mathrm{XPS}}$ value of 0.25 , while the supported Co-Mn mixed oxide catalysts obtained from carbonate precursors showed the highest activity at a $\mathrm{Co} /(\mathrm{Co}+\mathrm{Mn})_{\mathrm{XPS}}$ ratio of approximately 0.5 . The high catalytic activity of the catalyst with a $\mathrm{Co} /(\mathrm{Co}+\mathrm{Mn})_{\mathrm{XPS}}$ ratio of approximately 0.5 can be explained by the formation of $\mathrm{CoMnO}_{3}$, which, however, was not detected for the catalysts investigated in this study as evidenced by their Raman spectra and powder XRD patterns.

In our previous work [24], we have shown that the catalytic activity of the structured Co-Mn mixed oxides obtained from carbonate precursors under hydrothermal conditions correlated well with the amount of surface oxygen vacancies determined by XPS. Recently, surface oxygen vacancies have been found to play a key role in the oxidation of VOC [49]. These defect sites on the surface of metal oxides adsorb oxygen from the air and convert it into catalytically active species. Mitran et al. [45] also observed that substitution of $\mathrm{Co}^{3+}$ for $\mathrm{Mn}^{4+}$ in Co-Mn oxides up to $\mathrm{Mn}_{0.15} \mathrm{Co}_{2.85} \mathrm{O}_{\mathrm{x}}$ led to the formation of active sites for ethanol oxidation. The interaction of $\mathrm{Co}^{3+}$ and $\mathrm{Mn}^{4+}$ with lattice oxygen formed oxygen vacancies that served as catalytically active sites.

The interactions of the small $\mathrm{MnO}_{\mathrm{x}}$ or $\mathrm{CoMnO}_{\mathrm{x}}$ particles, produced by additional magnetron sputtering, with the larger electrochemically deposited cobalt oxide platelets were likely more complex and might influence the formation of oxygen vacancies. The complex morphology of the oxide layers observed in the prepared $\mathrm{CoO}_{\mathrm{x}}-\mathrm{MnO}_{\mathrm{x}}$ and $\mathrm{CoO}_{\mathrm{x}^{-}}$ 
$\mathrm{CoMnO}_{\mathrm{x}}$ catalysts probably plays a major role in their catalytic activity. On the other hand, large and roughly cubic crystals of carbonate precursors were formed on the stainless steel meshes during their hydrothermal treatment in aqueous solutions of Co and Mn nitrates in the presence of hydrolyzing urea; this morphology was preserved after calcination at $500{ }^{\circ} \mathrm{C}$, when the precursors were transformed into Co-Mn mixed oxides [10]. In Co-Mn mixed oxide catalysts obtained from hydrothermally crystallized carbonate precursors, a strong interaction between $\mathrm{Co}$ and $\mathrm{Mn}$ components was confirmed by $\mathrm{H}_{2}-\mathrm{TPR}$. The incorporation of $\mathrm{Mn}$ into Co oxide facilitated the reduction of cobalt oxide [10]. However, the presence of Mn components introduced over the cobalt oxide particles by RF magnetron sputtering showed a different pattern. The single component $\mathrm{MnO}_{\mathrm{x}}-2$ and $\mathrm{CoO}_{\mathrm{x}}-2$ catalysts showed the first reduction maxima at 321 and $366{ }^{\circ} \mathrm{C}$, respectively. For the cobalt oxide catalysts with $\mathrm{MnO}_{x}$ and $\mathrm{CoMnO}_{x}$ coatings, the position of the first reduction peak shifted with increasing $\mathrm{Co} /(\mathrm{Co}+\mathrm{Mn})_{\mathrm{EDX}}$ ratio (i.e., the bulk $\mathrm{Co} /(\mathrm{Co}+\mathrm{Mn})$ molar ratio) and a slight deterioration in the reducibility of the catalysts was observed (Figure 9). The maximum deterioration occurred at a $\mathrm{Co} /(\mathrm{Co}+\mathrm{Mn})_{\mathrm{EDX}}$ ratio of approximately 0.5 .

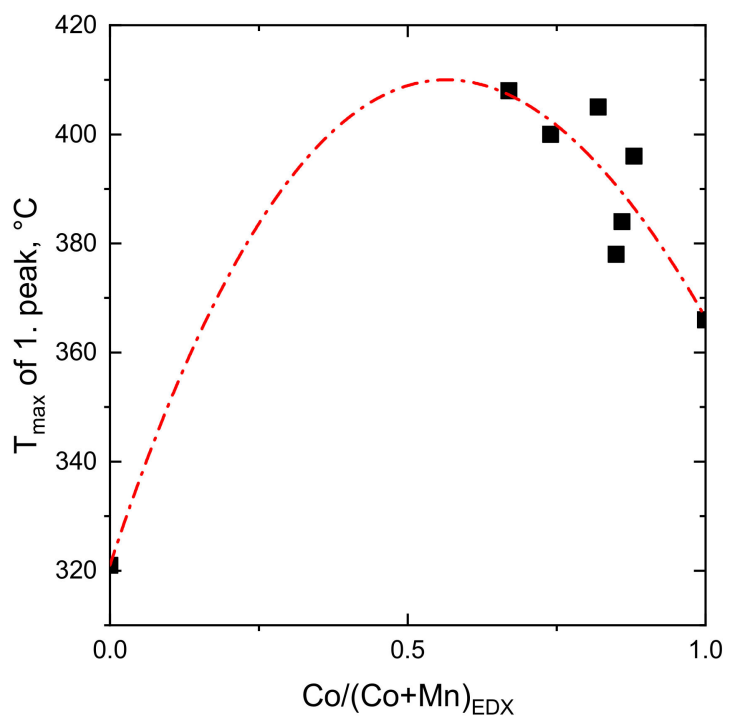

Figure 9. Relation between the $\mathrm{Co} /(\mathrm{Co}+\mathrm{Mn})$ molar ratio determined by EDX and the position of the first reduction peak in the $\mathrm{H}_{2}$-TPR experiments.

A good correlation between the hydrogen consumption obtained during $\mathrm{H}_{2}$-TPR experiments and the performance of Co-Mn oxide catalysts [50], as well as a good correlation between the position of the first reduction peak and the $T_{50}$ temperature during ethanol oxidation [51,52] was observed earlier. However, for cobalt oxide catalysts modified with additional $\mathrm{MnO}_{\mathrm{x}}$ coatings (deposited by plasma sputtering), the catalytic activity $\left(R_{200}\right)$ decreased with an increasing first reduction peak temperature, while the catalytic activity of cobalt oxide catalysts coated with $\mathrm{CoMnO}_{\mathrm{x}}$ oxides increased with an increasing first reduction peak temperature (Figure 10 left).

In contrast to the results reported in [50], a non-proportional dependence of $R_{200}$ on hydrogen consumption in the temperature range $25-500^{\circ} \mathrm{C}$ was found in this study (Figure 10 right). Cobalt oxide deposited on stainless steel meshes could react with sputtered $\mathrm{MnO}_{\mathrm{x}}$ and $\mathrm{CoMnO}_{\mathrm{x}}$ coatings to form components with impaired reducibility, although no such components were identified by powder XRD and Raman spectroscopy.

The supported cobalt oxide catalysts with $\mathrm{MnO}_{\mathrm{x}}$ and $\mathrm{CoMnO}_{\mathrm{x}}$ coatings produced by plasma sputtering showed better adhesion of the oxide layers to the stainless steel support than the supported catalysts coated with Co-Mn mixed oxides obtained by hydrothermal synthesis [10]. However, the significant improvement in the adhesion of the cobalt oxide layers modified with additional $\mathrm{MnO}_{\mathrm{x}}$ and $\mathrm{CoMnO}_{\mathrm{x}}$ coatings, observed previously for thin cobalt oxide layers additionally deposited by plasma sputtering [6], was not confirmed. 
Very likely, coating the cobalt oxide platelets, originating from the electrochemically deposited precursors, with small $\mathrm{MnO}_{\mathrm{x}}$ or $\mathrm{CoMnO}_{\mathrm{x}}$ particles could not sufficiently reinforce the cobalt oxide layer.
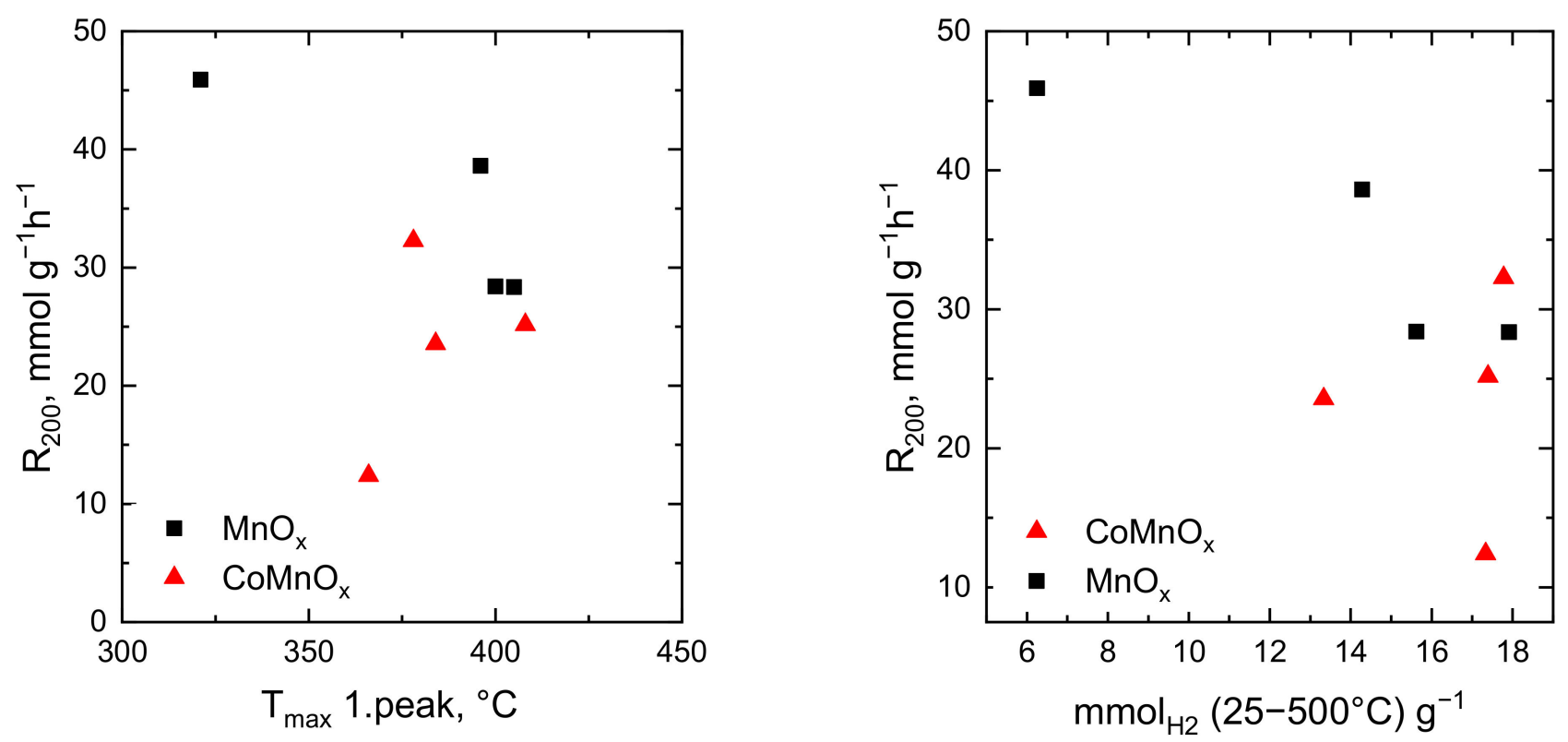

Figure 10. Dependence of $R_{200}$ value on the position of the first reduction peak (left) and hydrogen consumption per gram of oxides determined in the temperature range $25-500{ }^{\circ} \mathrm{C}$ (right) in the $\mathrm{H}_{2}-\mathrm{TPR}$ experiments.

\section{Conclusions}

The thin layer of cobalt oxide, obtained from the precursor electrochemically deposited on stainless steel meshes, was modified by additional thin coatings of $\mathrm{MnO}_{\mathrm{x}}$ and $\mathrm{CoMnO}_{\mathrm{x}}$ prepared by RF magnetron sputtering of $\mathrm{Mn}$ and $\mathrm{Co}+\mathrm{Mn}$ mixture in the $\mathrm{Ar}+\mathrm{O}_{2}$ atmosphere. The supported catalysts contained $0.45-0.75 \mathrm{wt} . \%$ of Co and Mn oxides.

In ethanol oxidation, the prepared catalysts showed better performance than the pelletized commercial Co-Mn-Al mixed oxide catalyst. Their catalytic activity was $23-87$ times higher, although the metal content in the catalytic bed was 360-570 times lower. The cobalt oxide with additional $\mathrm{MnO}_{x}$ coatings showed higher catalytic activity than the oxide coated with $\mathrm{CoMnO}_{\mathrm{x}}$ coatings.

In contrast to the previously studied Co-Mn mixed oxides obtained by hydrothermal synthesis, which exhibited the highest catalytic activity at a $\mathrm{Co} /(\mathrm{Co}+\mathrm{Mn})$ molar ratio of 0.5 , cobalt oxide catalysts modified with additional $\mathrm{MnO}_{\mathrm{x}}$ and $\mathrm{CoMnO}_{\mathrm{x}}$ thin coatings showed the highest catalytic activity at the $\mathrm{Co} /(\mathrm{Co}+\mathrm{Mn})$ ratio of 0.8 . The XPS measurements showed that $\mathrm{Co}^{2+}$ and $\mathrm{Co}^{3+}$ ions were present on the surface of the catalysts in the molar ratio of approximately 1:1. The Mn compounds were predominantly present on the surface of the catalysts as $\mathrm{Mn}^{3+}$ and outnumbered $\mathrm{Mn}^{4+}$ by a factor of 2-3, regardless of the metals used for magnetron sputtering.

Compared to the pelletized commercial Co-Mn-Al mixed oxide catalyst, the structured Co-Mn oxide catalysts exhibited significantly lower temperature required to achieve $90 \%$ conversion of ethanol to $\mathrm{CO}_{2}\left(282-307^{\circ} \mathrm{C}\right.$ versus $\left.405^{\circ} \mathrm{C}\right)$. The temperature reduction of approximately $100^{\circ} \mathrm{C}$ is important from an economic point of view: the lower reaction temperature will contribute to a reduction in operating costs.

This study provides new insights for the optimization of the magnetron sputtering process in the development of new supported catalysts not only for VOC oxidation. 


\section{Materials and Methods}

\subsection{Preparation of Catalysts}

The method described in our recent report [6] was used for the catalysts' preparation. Circular stainless steel meshes (71 wt.\% Fe, 16 wt.\% Cr, 11 wt.\% Ni, 2 wt.\% Mn, mesh size $0.40 \mathrm{~mm}$, and wire diameter $0.22 \mathrm{~mm}$ ) with an outer diameter of $25 \mathrm{~mm}$ were used as supports. The meshes were mechanically cleaned using a brush with detergent, then thoroughly washed in distilled water, and the cleaning process was finished by degreasing in acetone for $10 \mathrm{~min}$ in an ultrasonic bath. Furthermore, the standard ion scrubbing process was applied on the meshes before coating with the cobalt oxide thin film. The meshes were placed into the vacuum chamber onto substrate holder, which was connected to an RF power supply. The chamber was filled with the forming gas $\left(90\right.$ vol. $\% \mathrm{~N}_{2}, 10$ vol. $\% \mathrm{H}_{2}$ ) at pressure of $20 \mathrm{~Pa}$. The RF discharge was then ignited for $300 \mathrm{~s}$ with delivered power of $300 \mathrm{~W}$ to clean and activate the meshes' surface.

Following procedure was used for coating the stainless steel meshes with cobalt oxide thin film (thickness of about $300 \mathrm{~nm}$ ): The plasma sputtering deposition was carried out in a vacuum chamber Veeco evacuated by a turbomolecular pump to a base pressure lower than $10^{-4} \mathrm{~Pa}$. As a sputtering gun, the Kurt J. Lesker Torus $2 \mathrm{HV}$ magnetron equipped with high strength magnets in a balanced configuration of the magnetic field was used. Cobalt oxide thin films were sputtered from the cobalt target ( $99.95 \%$ Co, Kurt J. Lesker) of $50 \mathrm{~mm}$ in diameter and a thickness of $3 \mathrm{~mm}$. The argon and oxygen mass flow rates were held at 20 and $55 \mathrm{~mL} \mathrm{~min}^{-1}$ under standard conditions, respectively. The working pressure of $2.5 \mathrm{~Pa}$ was adjusted by the gate valve throttling the turbomolecular pump. A grounded substrate holder, able to accommodate six meshes (electrically connected with the holder), was placed at axial distance of $70 \mathrm{~mm}$ from the target face; this distance ensured homogeneity of the film thickness better than $5 \%$ for all the meshes placed on the holder. The deposition by RF magnetron sputtering was carried out for $30 \mathrm{~min}$ using the planar magnetron connected to a RF power supply Advanced Energy ATX 600, supplying $200 \mathrm{~W}$ into the discharge. The deposition process was repeated in order to cover both sides of the meshes.

The stainless steel meshes coated with thin cobalt oxide films were used as substrates for subsequent electrochemical treatment. The electrochemical reaction was performed at room temperature in $\mathrm{Co}\left(\mathrm{NO}_{3}\right)_{2}$ aqueous solution $\left(0.10 \mathrm{~mol}^{-1}\right)$ in the presence of $\mathrm{KNO}_{3}$ $\left(0.25 \mathrm{~mol} \mathrm{l}^{-1}\right)$ as a supporting electrolyte in galvanostatic mode at $20 \mathrm{~mA}$ and deposition time of $20 \mathrm{~min}$; two platinum sheets were used as anodes and the stainless steel mesh (cathode) was placed between them. Then the meshes were washed with distilled water, dried at $60{ }^{\circ} \mathrm{C}$, and calcined at $500{ }^{\circ} \mathrm{C}$ for $4 \mathrm{~h}$ in air.

Finally, the additional $\mathrm{MnO}_{\mathrm{x}}$ or $\mathrm{CoMnO}_{\mathrm{x}}$ coatings were deposited by reactive $\mathrm{RF}$ magnetron sputtering in the oxidation $\mathrm{Ar}+\mathrm{O}_{2}$ atmosphere; sputtering from the manganese target $(99.95 \% \mathrm{Mn}$, Kurt J. Lesker) and simultaneous sputtering from the cobalt and manganese targets were applied for deposition of the $\mathrm{MnO}_{\mathrm{x}}$ and $\mathrm{CoMnO}_{\mathrm{x}}$ coatings, respectively. Duration of the magnetron sputtering process was varied to obtain various thicknesses of the $\mathrm{MnO}_{\mathrm{x}}$ and $\mathrm{CoMnO}_{\mathrm{x}}$ coatings $(0.1,0.2$, and $0.3 \mu \mathrm{m})$. A relation between the deposition time and thickness of the coatings was obtained from the magnetron sputtering experiments carried out at the same conditions with planar glass substrates, when thickness of the coatings was measured by a profilometer. According to the expected coatings thickness, the prepared samples are labeled as $\mathrm{MnO}_{\mathrm{x}}-0.1, \mathrm{MnO}_{\mathrm{x}}-0.2, \mathrm{MnO}_{\mathrm{x}}-0.3$, $\mathrm{CoMnO}_{\mathrm{x}}-0.1, \mathrm{CoMnO}_{\mathrm{x}}-0.2$, and $\mathrm{CoMnO}_{\mathrm{x}}-0.3$. After deposition of the $\mathrm{MnO}_{\mathrm{x}}$ or $\mathrm{CoMnO}_{\mathrm{x}}$ coatings, the samples were calcined for $4 \mathrm{~h}$ at $500{ }^{\circ} \mathrm{C}$ in air.

The samples with thicker cobalt and manganese oxide coatings (about $2 \mu \mathrm{m}$ ) were also prepared by long-term RF magnetron sputtering and then calcined for $4 \mathrm{~h}$ at $500{ }^{\circ} \mathrm{C}$ in air; these catalysts are labeled as $\mathrm{MnO}_{\mathrm{x}}-2$ and $\mathrm{CoO}_{\mathrm{x}}-2$. 


\subsection{Catalyst Characterization}

The Co and Mn contents in the deposited oxides were determined using the following way-small amounts of the solids were gained by brushing of the meshes immersed in a container filled with acetone and placed in an ultrasonic bath. After the drying, the obtained solids were analysed by Energy-dispersive X-ray spectroscopy (EDX, Quantax 200, Bruker, Billerica, MA, USA).

Thickness of the films prepared on glass substrates by RF magnetron sputtering was measured by a profilometer Alpha-Step IQ (KLA-Tencor, Milpitas, CA, USA).

Adhesion of the deposited layers to the stainless steel supports was determined from comparison of the weight loss after 10 min treatment in an ultrasonic bath SONOREX Digital 10P; the samples were immersed in acetone. The difference between the initial weight and the weight of the dried samples after treatment in ultrasonic bath was related to the weight of deposited oxides.

Powder X-ray diffraction (XRD) patterns were recorded using a Bruker AXS D8 diffractometer (Bruker, Berlin, Germany) with Co K $\alpha$ radiation $(\lambda=0.179 \mathrm{~nm})$ in $2 \theta$ range $20-80^{\circ}$, step size $0.02^{\circ}$. The qualitative analysis was performed with a HighScore Plus 4.8 software package (PANanalytical, Malvern, United Kingdom, 2018). Lattice parameters were evaluated using the cell refinement and profile fitting. The mean coherence lengths (considered as approximate crystallite sizes) were evaluated using the Scherrer equation. The pellets of the Com catalyst were grinded before the XRD measurement and no other components were added to the sample.

The sample morphology was investigated using scanning electron microscopy with a FEG electron gun (FIB-SEM TESCAN LYRA 3 GMU, TESCAN ORSAY HOLDING, Brno, Czech Republic) at the acceleration voltage of $10 \mathrm{kV}$. We prepared the sample cross-section by two techniques: The first technique used Scotch tape to remove the top catalytic layer from the supporting stainless steel mesh. The second technique, applied to a mechanically stable catalytic layer, used a focused ion beam (FIB) to create a trench in the raw sample and polish one side of the trench to reveal the cross-section structure. To prevent undesirable damage to the sample surface during FIB irradiation, we applied a protective layer of platinum to the exposed surface using a built-in gas injection system (GIS) before preparing the trench. All cross-section images were taken with a 55 degree tilt according to the electron beam. Surface morphology of the mixed oxides particles deposited on the stainless steel supports was observed using scanning electron microscope Tescan FERA 3.

Surface area of the catalysts was determined from the adsorption isotherms of physisorbed krypton as described elsewhere using a specially designed stainless steel vessel for measurements of bulky catalysts [53] enabling measurements of surfaces of large samples $(<30 \mathrm{~mm})$ in the device of ASAP, Micromeritics, Norcross, Atlanta, GA, USA.

$\mathrm{H}_{2}$-TPR with TCD detector was done using $10 \mathrm{~mol} . \% \mathrm{H}_{2}$ in nitrogen and $20{ }^{\circ} \mathrm{C}$ $\min ^{-1}$ temperature ramp. Changes in $\mathrm{H}_{2}$ concentration were detected with a catharometer. Reduction of the grained $\mathrm{CuO}(0.160-0.315 \mathrm{~mm})$ was performed to calculate absolute values of the hydrogen consumed during reduction of the samples.

FTIR (Fourier-transform infrared spectrometer) Avatar 360 (Nicolet) (Analytical Instruments Brokers LLC, MN, U.S.A.) was used to measure infrared spectra of samples between 360 and $4000 \mathrm{~cm}^{-1}$ (resolution $1.93 \mathrm{~cm}^{-1}, 300 \mathrm{scans}, 1 \mathrm{~s}$ per scan). FTIR was used in specular reflection mode to obtain spectra from the catalysts deposited on stainless steel meshes while pristine stainless steel mesh was used as a background. The spectrum of pelletized $\mathrm{Co}-\mathrm{Mn}-\mathrm{Al}$ mixed oxide catalyst was obtained in a common ATR mode when a pellet was crushed and the arising powder was pressed against the ZnSe crystal.

Raman spectra were measured using a DXR Microscope dispersive Raman spectrometer (Thermo Scientific, Brno, Czech Republic) equipped with an Olympus confocal microscope and a thermoelectrically cooled CCD detector. A solid-state Nd:YAG laser (wavelength $532 \mathrm{~nm}$, maximum power $10 \mathrm{~mW}$ ) was used as excitation source. A 900 lines/mm grating, 50x magnification objective, laser power of $0.3 \mathrm{~mW}$, acquisition time of $30 \mathrm{~s}$ per scan and 40 repetitions were used to collect the spectra. 
Surface elemental analyses were performed using a Kratos ESCA $3400 \mathrm{X}$-ray photoelectron spectrometer (X-ray photoelectron spectrometry ESCA 3400, Kratos, Manchester, UK). The samples were placed on a carbon tape. From that reason, a carbon correction was not possible. Therefore, all spectra were corrected to a metal bound oxygen (529.6 eV). Shirley background was subtracted and elemental compositions of the layers were calculated from the corresponding areas. The Co $2 \mathrm{p}_{3 / 2}$ peak fitting was done with respect to Biesinger et al. [37] and our previous works [40,54] in order to be consistent.

\title{
5.3. Catalytic Experiments
}

The catalytic tests in total oxidation of ethanol were performed with $760 \mathrm{ppm}$ of ethanol in air at GHSV of $21 \mathrm{~g}_{\mathrm{cat}}{ }^{-1} \mathrm{~h}^{-1}$ using a fixed-bed reactor and a temperature ramp of $2{ }^{\circ} \mathrm{C} \mathrm{min}{ }^{-1}$. The $T_{50}$ temperature, at which $50 \%$ of ethanol conversion was achieved, was used to compare the performance of the catalysts. Catalytic activity was evaluated as $R_{200}$ (amount of ethanol converted per gram of oxides and hour at $200{ }^{\circ} \mathrm{C}$ ). The $T_{90}\left(\mathrm{CO}_{2}\right)$ temperature, at which $90 \%$ conversion to $\mathrm{CO}_{2}$ was achieved, was employed to compare the effectiveness of the catalysts. The pelletized commercial Co-Mn-Al mixed oxide catalyst (Astin 2-100, Czech Republic, Co:Mn:Al molar ratio of 4:1:1, pellets $5 \times 5 \mathrm{~mm}$ ), labelled as Com, was tested under the same reaction conditions for comparison.

Supplementary Materials: The following are available online at https: / www.mdpi.com/article/ 10.3390 / catal11121453/s1, Figure S1: Powder XRD pattern of the pelletized commercial Co-Mn-Al mixed oxide (the Com sample). S-Co-Mn-Al spinel, G-graphite, Figure S2: Deconvolution of Co $2 p, M n 2 p$, and O 1s spectra of the investigated samples.

Author Contributions: Conceptualization, F.K.; methodology, K.J., Z.H., M.Č. and M.K.; validation, M.K., F.K. and K.J.; investigation, R.P., M.D., J.B., M.K., P.T., D.P. and M.V.; data curation, J.B. and M.K.; writing—original draft preparation, K.J. and F.K.; writing—review and editing, K.J., F.K., M.K., Z.H. and P.T.; supervision, M.Č.; project administration, M.Č., F.K. and K.J. All authors have read and agreed to the published version of the manuscript.

Funding: The authors thank the Czech Science Foundation (project No. 21-04477S) for financial support.

Institutional Review Board Statement: Not applicable.

Informed Consent Statement: Not applicable.

Acknowledgments: The authors thank H. Šnajdaufová for the measurement of surface area of the catalysts.

Conflicts of Interest: The authors declare no conflict of interest.

\author{
Abbreviations \\ VOC volatile organic compounds \\ RF radio frequency magnetron sputtering \\ ED electrochemical deposition \\ Com commercial catalyst Astin 2-100 \\ XRD X-ray diffraction \\ SEM Scanning electron microscopy \\ FTIR Fourier-transform infrared spectroscopy \\ TPR temperature programmed reduction \\ XPS X-ray photoelectron spectroscopy \\ AcA acetaldehyde \\ EtOH Ethanol
}




\section{References}

1. Duprez, D.; Cavani, F. Handbook of Advanced Methods and Processes in Oxidation Catalysis; Imperial College Press: London, UK, 2014. [CrossRef]

2. Ojala, S.; Pitkaaho, S.; Laitinen, T.; Koivikko, N.N.; Brahmi, R.; Gaalova, J.; Matějova, L.; Kucherov, A.; Paivarinta, S.; Hirscmann, C.; et al. Catalysis in VOC abatement. Top. Catal. 2011, 54, 1224-1256. [CrossRef]

3. Suib, S.L. (Ed.) New and Future Developments in Catalysis; Elsevier: Amsterdam, The Netherlands, 2013 ; ISBN 9780444538741.

4. Jiratova, K.; Kovanda, F.; Balabanova, J.; Kširova, P. Aluminum wire meshes coated with Co and Co-Mn-Al oxides as catalysts for deep ethanol oxidation. Catal. Today 2018, 304, 165-171. [CrossRef]

5. Topka, P.; Dvořáková, M.; Kšírová, P.; Perekrestov, R.; Čada, M.; Balabánová, J.; Koštejn, M.; Jirátová, K.; Kovanda, F. Structured cobalt oxide catalysts for VOC abatement: The effect of preparation method. Environ. Sci. Pollut. Res. 2020, 27, 7608-7617. [CrossRef] [PubMed]

6. Dvořáková, M.; Perekrestov, R.; Kšírová, P.; Balabánová, J.; Jirátová, K.; Maixner, J.; Topka, P.; Rathouský, J.; Koštejn, M.; Čada, M.; et al. Preparation of cobalt oxide catalysts on stainless steel wire mesh by combination of magnetron sputtering and electrochemical deposition. Catal. Today 2019, 334, 13-23. [CrossRef]

7. Kovanda, F.; Jirátová, K.; Ludvíková, J.; Raabová, H. Co-Mn-Al mixed oxides on anodized aluminum supports and their use as catalysts in the total oxidation of ethanol. Appl. Catal. A Gen. 2013, 464-465, 181-190. [CrossRef]

8. Cai, T.; Huang, H.; Deng, W.; Dai, Q.; Liu, W.; Wang, X. Catalytic combustion of 1,2-dichlorobenzene at low temperature over Mn-modified $\mathrm{Co}_{3} \mathrm{O}_{4}$ catalysts. Appl. Catal. B 2015, 166-167, 393-405. [CrossRef]

9. Zhang, W.D.; Anguita, P.; Diez-Ramirez, J.; Descorme, C.; Valverde, J.L.; Giroir-Fendler, A. Comparison of Different Metal Doping Effects on $\mathrm{Co}_{3} \mathrm{O}_{4}$ Catalysts for the Total Oxidation of Toluene and Propane. Catalysts 2020, 10, 865. [CrossRef]

10. Topka, P.; Jirátová, K.; Dvořáková, M.; Balabánová, J.; Koštejn, M.; Kovanda, F. Hydrothermal deposition as a novel method 1 for the preparation of Co-Mn mixed oxide catalysts supported on stainless steel meshes: Application to VOC oxidation. Environ. Sci. Pollut. Res. 2021. [CrossRef]

11. Tang, W.; Wu, X.; Li, S.; Li, W.; Chen, Y. Porous Mn-Co mixed oxide nanorod as a novel catalyst with enhanced catalytic activity for removal of VOCs. Catal. Comm. 2014, 56, 134-138. [CrossRef]

12. Masi, A.; Bellusci, M.; Carlini, M.; McPhail, S.; Padella, F.; Reale, P. Mechanochemical Processing of Mn and Co Oxides: An Alternative Way to Synthesize Mixed Spinels for Protective Coating. J. Am. Ceram. Soc. 2015, 99, 308-314. [CrossRef]

13. Liang, Q.; Chen, K.; Hou, W.; Yan, Q. CO hydrogenation over nanometer spinel-type Co/Mn complex oxides prepared by sol-gel method. Appl. Catal. A 1998, 166, 191-199. [CrossRef]

14. Venkateswarlu, P.; Umeshbabu, E.; Kumar, U.N.; Nagaraja, P.; Tirupathi, P.; Rao, G.R.; Justin, P. Facile hydrothermal synthesis of urchin-like cobalt manganese spinel for high-performance supercapacitor applications. J. Colloid Interface Sci. 2017, 503, 17-27. [CrossRef]

15. Bian, N. Investigations on Hydrothermally Synthesized Co3O4/MnxCo3-xO4 Core-Shell Nanoparticles. Master's Thesis, Missouri State University, Springfield, MO, USA, 2018.

16. Hurst, N.W.; Gentry, S.J.; Jones, A.; McNicol, B.D. Temperature Programmed Reduction. Catal. Rev. Sci. Eng. 1982, $24,233-309$. [CrossRef]

17. Calgaro, C.O.; Perez-Lopez, O.W. Decomposition of methane over Co3-xAlxO4 (x=0-2) coprecipitated catalysts: The role of Co phases in the activity and stability. Int. J. Hydrog. Energy 2017, 42, 29756-29772. [CrossRef]

18. Lin, H.; Chen, Y.-W. The mechanism of reduction of cobalt by hydrogen. Mater. Chem. Phys. 2004, 85, 171-175. [CrossRef]

19. Wu, M.; Zhan, W.; Guo, Y.; Guo, Y.; Wang, Y.; Wang, L.; Lu, G. An effective Mn-Co mixed oxide catalyst for the solvent-free selective oxidation of cyclohexane with molecular oxygen. Appl. Catal. A 2016, 523, 97-106. [CrossRef]

20. Chen, A.; Xu, H.; Yue, Y.; Hua, W.; Shen, W.; Gao, Z. Hydrogenation of methyl benzoate over manganese oxide catalysts prepared from Mn/Mn/Al hydrotalcite-like compounds. Appl. Catal. A 2004, 274, 101-109. [CrossRef]

21. Arena, F.; Torre, T.; Raimondo, C.; Parmaliana, A. Structure and redox properties of bulk and supported manganese oxide catalysts. Phys. Chem. Chem. Phys. 2001, 3, 1911-1917. [CrossRef]

22. Bulavchenko, O.A.; Gerasimov, E.Y.; Afonasenko, T.N. Reduction of double manganese-cobalt oxides: In situ XRD and TPR study. Dalton Trans. 2018, 47, 17153-17159. [CrossRef]

23. Li, W.; Yang, S.; Wang, K.; Tu, S.; Lu, M.; Wu, P. Evaluation of the physiochemical properties and catalytic performance of $\mathrm{CuCoMnAl}$ mixed oxides derived from layered double hydroxides precursors with different mole ratios of $\mathrm{Cu} / \mathrm{Co}$ on the oxidation of toluene. React. Kinet. Mech. Catal. 2019, 128, 965-977. [CrossRef]

24. Bentley, F.F.; Smithson, L.D.; Rozek, A.L. Infrared Spectra and Characteristic Frequencies [Equivalency Symbol] 700-300 $\mathrm{cm}^{-1}$ : Collection of Spectra, Interpretation, and Bibliography; Interscience: Saint Nom la Brétèche, France, 1968.

25. Jirátová, K.; Balabánová, J.; Kovanda, F.; Klegová, A.; Obalová, L.; Fajgar, R. Cobalt Oxides Supported Over Ceria-Zirconia Coated Cordierite Monoliths as Catalysts for Deep Oxidation of Ethanol and $\mathrm{N}_{2}$ O Decomposition. Catal. Lett. 2017, 147, 1379-1391. [CrossRef]

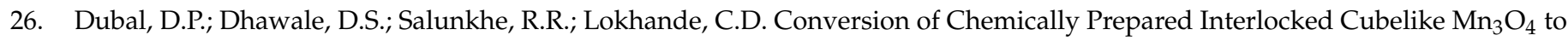
Birnessite MnO2 Using Electrochemical Cycling. J. Electrochem. Soc. 2010, 157, A812-A817. [CrossRef]

27. Wu, S.; Xie, M.; Zhang, Q.; Zhong, L.; Muhan, C.; Huang, Z. Isopentyl-Sulfide-Impregnated Nano-MnO ${ }_{2}$ for the Selective Sorption of $\mathrm{Pd}(\mathrm{II})$ from the Leaching Liquor of Ores. Molecules 2017, 22, 1117. [CrossRef] 
28. Habibi, M.H.; Bagheri, P. Spinel cobalt manganese oxide nano-composites grown hydrothermally on nanosheets for enhanced photocatalytic mineralization of Acid Black 1 textile dye: XRD, FTIR, FESEM, EDS and TOC studies. J. Iran. Chem. Soc. 2017, 14, 1643-1649. [CrossRef]

29. Martin de Vidales, J.L.; Vila, E.; Rojas, R.M.; Garcia-Martinez, O. Thermal Behavior in Air and Reactivity in Acid Medium of Cobalt Manganese Spinels $\mathrm{Mn}_{\mathrm{x}} \mathrm{Co}_{3-\mathrm{x}} \mathrm{O}_{4}$ Synthesized at Low Temperature. Chem. Mater. 1995, 7, 1716-1721. [CrossRef]

30. Tholkappiyan, R.; Naveen, A.N.; Sumithra, S.; Vishista, K. Investigation on spinel MnCo2O4 electrode material prepared via controlled and uncontrolled synthesis route for supercapacitor application. J. Mater. Sci. 2015, 50, 5833-5843. [CrossRef]

31. Hadjiev, V.G.; Iliev, M.N.; Vergilov, I.V. The Raman spectra of $\mathrm{Co}_{3} \mathrm{O}_{4}$. J. Phys. Chem. Solid State Phys. 1998, $21, \mathrm{~L} 199-\mathrm{L} 201$. [CrossRef]

32. Tang, C.; Wang, C.; Chien, S. Characterization of cobalt oxides studied by FT-IR, Raman, TPR and TG-MS. Thermochim. Acta 2008, 473, 68-73. [CrossRef]

33. Li, Y.; Qiu, W.; Qin, F.; Fang, H.; Hadjiev, V.G.; Litvinov, D.; Bao, J. Identification of Cobalt Oxides with Raman Scattering and Fourier Transform Infrared Spectroscopy. J. Phys. Chem. C 2016, 120, 4511-4516. [CrossRef]

34. Gao, T.; Fjellvíg, H.; Norby, P. A comparison study on Raman scattering properties of alfa- and beta-MnO2. Anal. Chim. Acta 2009, 648, 235-239. [CrossRef]

35. Kim, K.-H.; Lee, D.K.; Choi, Y.-H. Fabrication of Single-Phase Manganese Oxide Films by Metal-Organic Decomposition. Materials 2021, 14, 2338. [CrossRef]

36. Wang, J.Y.; Kuang, P.Y.; Li, N.; Liu, Z.Q.; Su, Y.Z.; Chen, S. Facile hydrothermal synthesis of cobalt manganese oxides spindles and their magnetic properties. Ceram. Int. 2015, 41, 8670-8679. [CrossRef]

37. Biesinger, M.C.; Payne, B.P.; Grosvenor, A.P.; Lau, L.W.M.; Gerson, A.R.; Smart, R.S.C. Resolving surface chemical states in XPS analysis of first row transition metals, oxides and hydroxides: Cr, Mn, Fe, Co and Ni. Appl. Surf. Sci. 2011, 257, 2717-2730. [CrossRef]

38. Hagelin-Weaver, H.A.E.; Hoflund, G.B.; Minahan, D.M.; Salaita, G.N. Electron energy loss spectroscopic investigation of Co metal, $\mathrm{CoO}$, and $\mathrm{Co}_{3} \mathrm{O}_{4}$ before and after Ar+ bombardment. Appl. Surf. Sci. 2004, 235, 420-448. [CrossRef]

39. Obalová, L.; Karásková, K.; Wach, A.; Kustrowski, P.; Mamulová-Kutláková, K.; Michalik, S.; Jirátová, K. Alkali metals as promoters in Co-Mn-Al mixed oxide for $\mathrm{N}_{2} \mathrm{O}$ decomposition. Appl. Catal. A 2013, 462-463, 227-235. [CrossRef]

40. Obalová, L.; Pacultová, K.; Balabánová, J.; Jirátová, K.; Bastl, Z.; Valášková, M.; Lacný, Z.; Kovanda, F. Effect of Mn/Al ratio in Co-Mn-Al mixed oxide catalysts prepared from hydrotalcite-like precursors on catalytic decomposition of $\mathrm{N}_{2} \mathrm{O}$. Catal. Today 2007, 119, 233-238. [CrossRef]

41. Langell, M.A.; Gevrey, F.; Nydegger, M.W. Surface composition of MnxCo1-xO solid solution by X-ray photoelectron and Auger spectroscopies. Appl. Surf. Sci. 2000, 153, 114-127. [CrossRef]

42. Iablokov, V.; Barbosa, R.; Pollefeyt, G.; Van Driessche, I.; Chenakin, S.; Kruse, N. Catalytic CO Oxidation over Well-Defined Cobalt Oxide Nanoparticles: Size-Reactivity Correlation. ACS Catal. 2015, 5, 5714-5718. [CrossRef]

43. Kim, S.C.; Shim, W.G. Catalytic combustion of VOCs over a series of manganese oxide catalysts. Appl. Catal. B 2010, 98, 180-185. [CrossRef]

44. Pacultova, K.; Bilkova, T.; Klegova, A.; Karaskova, K.; Fridrichova, D.; Jiratova, K.; Kiska, T.; Balabanova, J.; Kostejn, M.; Kotarba, A.; et al. Co-Mn-Al Mixed Oxides Promoted by K for Direct NO Decomposition: Effect of Preparation Parameters. Catalysts 2019, 9, 539. [CrossRef]

45. Mitran, G.; Chen, S.; Seo, D.-K. Role of oxygen vacancies and $\mathrm{Mn}^{4+} / \mathrm{Mn}^{3+}$ ratio in oxidation and dry reforming over cobaltmanganese spinel oxides. Mol. Catal. 2020, 483, 110704-110712. [CrossRef]

46. Feng, Z.; Bao, W.; Xu, X.; Ma, X.; Zhan, J.; Yin, Y. Heteroepitaxial Growth of Well-Dispersed $\mathrm{Co}_{3} \mathrm{O}_{4}$ Nanocatalysts on Porous ZnO Nanoplates via Successive Hydrothermal Deposition. Chem. Nano. Mat. 2016, 2, 946-951. [CrossRef]

47. Wang, K.; Cao, Y.; Hu, J.; Li, Y.; Xie, J.; Jia, D. Solvent-Free Chemical Approach to Synthesize Various Morphological Co3O4 for CO Oxidation. ACS Appl. Mater. Interfaces 2017, 9, 16128-16137. [CrossRef]

48. Matějová, L.; Topka, P.; Jirátová, K.; Šolcová, O. Total oxidation of model volatile organic compounds over some commercial catalysts. Appl. Catal. A 2012, 443, 40-49. [CrossRef]

49. Yang, X.; Yu, X.; Jing, M.; Song, W.; Liu, J.; Ge, M. Defective $\mathrm{Mn}_{\mathrm{x}} \mathrm{Zr}_{1-\mathrm{x}} \mathrm{O}_{2}$ Solid Solution for the Catalytic Oxidation of Toluene: Insights into the Oxygen Vacancy Contribution. ACS Appl. Mater. Interfaces 2019, 11, 730-739. [CrossRef]

50. Ludvíková, J.; Jirátová, K.; Klempa, J.; Raabová, H.; Zapivovarski Votipka, Z.; Kovanda, F. Ethanol Total Oxidation Over Calcined Layered Double Hydroxides Modified with Organic Components. Kem. Ind. 2013, 62, 137-146.

51. Topka, P.; Klementová, M. Total oxidation of ethanol over Au/ $\mathrm{Ce}_{0.5} \mathrm{Zr}_{0.5} \mathrm{O}_{2}$ cordierite monolithic catalysts. Appl. Catal. A 2016, 522, 130-137. [CrossRef]

52. Gaálová, J.; Topka, P.; Kaluža, L.; Soukup, K.; Barbier, J., Jr. Effect of gold loading on ceria-zirconia support in total oxidation of VOCs. Catal. Today 2019, 333, 190-195. [CrossRef]

53. Topka, P.; Jirátová, K.; Soukup, K.; Goliáš, J. Device for Measuring Specific Surface of Large Samples, Method of Measurement and Its Use. Czech Patent CZ308606, 2020.

54. Chromčáková, Ž.; Obalová, L.; Kovanda, F.; Legut, D.; Titov, A.; Ritz, M.; Fridrichová, D.; Michalik, S.; Kuśtrowski, P.; Jirátová, K. Effect of Precursor synthesis on catalytic activity of $\mathrm{Co}_{3} \mathrm{O}_{4}$ in $\mathrm{N}_{2} \mathrm{O}$ decomposition. Catal. Today 2015, 257, 18-25. [CrossRef] 